\title{
Are local public services better delivered in more autonomous regions? Evidence from European regions using a dose-response approach
}

\author{
Andrea Filippetti \\ National Research Council of Italy, Institute of Regional Studies (ISSiRFA), London School of \\ Economics and Political Science, Department of Geography and Environment, and Center for \\ Innovation Management Research, Birkbeck University of London \\ andrea.filippetti@cnr.it \\ a.filippetti@Ise.ac.uk

\section{Giovanni Cerulli} \\ National Research Council of Italy, IRCrES - Research Institute on Sustainable Economic Growth \\ giovanni.cerulli@ircres.cnr.it
}

\begin{abstract}
Does regional autonomy lead to better local public services? We investigate this issue using measures of public service performance and autonomy at the region level in 171 European regions. We introduce a novel dose-response approach which identifies the pattern of the effect of regional autonomy on the performance of public services. The relationship between the level of regional autonomy and the provision of local public services exhibits a u-shape: both low and high autonomy lead to better local public services. This speaks against the optimal level of autonomy and policy recommendations based on the view that more decentralisation is always desirable. It shows that different institutional settings can be economically viable and efficient.
\end{abstract}

JEL classification: P48; R1; R5; H7

Key words: quality of local public services; quality of institutions; decentralization; regional autonomy; European regions; dose-response approach 


\section{Introduction}

Does regional autonomy lead to a better provision of local public services? This question derives from a key argument in decentralization theory claiming that regional autonomy improves the quality of local governments, both in terms of the efficiency and the level in the provision of public goods (Hayek, 1945; Olson, 1993; Tiebout, 1956), accountability to citizens' preferences (Oates, 1972), and control of the public expenditure (Brennan and Buchanan, 1980; González-Alegre, 2015; Liberati and Sacchi, 2013). This claim has been recently challenged by several counter-arguments. Inter-jurisdictional competition may lead to a race to the bottom at the expenses of government quality; local governments can be more easily captured; fiscal "over-grazing" might occur when citizens are less capable of attributing merits or blame to different governments level (e.g. Breton, 2002; Kyriacou and Roca-Sagalés, 2011; Oates, 2005; Tanzi, 2001; Treisman, 2007).

As a matter of fact, decentralization has become quite popular over the past decades and virtually every country today is confronted with the opportunity to whether introduce decentralization reforms or not. In several cases decentralization reforms have been the results of bottom-up political processes in which citizens and local governments themselves have asked central government to provide for greater autonomy in terms of political power and fiscal resources. The recent referendum in Scotland, the Constitutional reform in Italy started in 2001, and the claims for independence of Cataluña in Spain are just a few cases in points. These instances of local autonomy can depend on different circumstances, some having long-standing historical roots, other some contingent motives such as the pressure of globalization or supra-national regional integration (Bache and Jones, 2000; Ermini and Santolini, 2014). However, the economic factor has become prominent in the decentralisation discourse (Rodriguez-Pose and Sandall, 2008). At the core of the instances for greater decentralization there is the view that when local governments are provided with more resource and entitled with higher autonomy and political legitimacy, this should improve the provisions of local public goods and services. If this is so, this should be reflected into the perceptions of citizens.

The organization for the provision of local public services differs across countries. First of all, the organization of public services depends upon the type of states, which can be grouped in three broad categories, namely federal states, regionalized states, unitary states. Accordingly, the allocation of competences varies considerably, distinguishing between exclusive competences and shared competences; in addition, competences can be divided into legislative and administrative. Usually, in unitary states the legislative competences belong to the central government, while administrative competences can be attributed to different levels of governments. In decentralized settings, such as federal or regionalized countries, the legislative competences of some local services can be attributed to the regional level. Taxation for public services also varies considerably across countries, some in which regional governments have taxation power; others in which the bulk of the services are financed thought a mechanism of transfers from the central government. As a result, it is easy to observe a great deal of heterogeneity when it comes to the regional competences across countries regarding the provision of public services, even when they are local services, such as for instance in the cases of education, public transport, health, police, etc (see European Institute of Public Administration (EIPA), 2012). There are countries such as Bulgaria, Estonia, Lithuania, the Netherlands, Slovenia and Sweden where regions have no specific competences on their own; 
federal countries like Belgium, in which regional governments have no competences on education, or like Germany, in which instead the Lands have competences above a large number of services. Similar patterns can be found for other local public services (e.g. health) (see also Sacchi and Salotti, 2014). ${ }^{1}$

Grounded on the theory of fiscal federalism and decentralization, this paper aims to test whether local public services are better (in terms of citizens' satisfaction) in countries in which regional governments retain greater autonomy in their provision. We employ a comprehensive measure of decentralization (or regional authority) to capture the different organizational structure of the provision of local public services, and a measure of the satisfaction of residents on local public services to capture their quality. Two contributions are provided. Firstly, we take the region as the unit of analysis - in a sample of 171 European regions - employing measures of local public service quality and autonomy of local governments at the region level. Secondly, we introduce a novel methodology based on a dose-response approach that has important advantages compared to traditional regression models, in that allows us to identify the entire pattern of the effect of regional autonomy along the quality of local public services.

The relationship between the quality of local public services and regional autonomy (or decentralization) has been addressed within that strand of literature which examines the relationship between decentralization and the quality of government (or quality of institutions). Most of these studies are based on cross-country and country based analysis. ${ }^{2}$ There are both theoretical and practical reasons for that. Regional autonomy is supposed to improve the overall quality of government, and hence analysis should not be limited to sub-national governments (Treisman, 2007). Data on the quality of government are quite rich at the country level and scarce at the region level. A number of indicators are provided for a large set of countries and a long span of time, such as the case of the Worldwide Governance Indicators (WGI) developed by World Bank, which is quite popular in these studies. Finally, several countries have introduced decentralization reforms over the past decades to increase their economic performance and this has spurred increasing interest for cross-country empirical work.

However, conducting the analysis at the country level also raises some issues. Firstly, in order to rely on a sufficient size of the sample, countries that are quite heterogeneous tend to be included. In these cases results can be driven by some groups of countries; to this regard, negative effect of decentralization are very often found to depend on less-developed countries (Blanchard and Shleifer, 2000; O'Dwyer and Ziblatt, 2006). Secondly, studying the effect of decentralization on the overall quality of government implies a long causal chain going from the local level to the aggregate level which can take time to take place and can depend on several other circumstances. Thirdly and

\footnotetext{
${ }^{1} \mathrm{~A}$ comprehensive report on this issue can be consulted here: http://www.cesifogroup.de/ifoHome/facts/DICE/Other-Topics/Structural-Policy/Regional-Policy/DP-MC-reg-comp/fileBinary/DPMC-reg-comp.pdf.

${ }^{2}$ See (Bae et al., 2015; e.g. Bartolini and Santolini, 2012; Fisman and Gatti, 2002; Grassmueck and Shields, 2010; Kyriacou et al., 2015; Thornton, 2007). Those works looking at the sub-national level tend to be based on a case-study approach (Enikolopov and Zhuravskaya, 2007; Faguet, 2004). In a recent paper Diaz-Serrano and Rodríguez-Pose (2011) takes a different perspective much similar to ours. Using micro data from the European social survey in 29 European countries, they find that political and fiscal decentralization have a positive and significant effect on individuals' overall happiness, as well as satisfaction with political and economic institutions and with the education and health systems.
} 
more importantly, the essence of fiscal decentralization theory claims that in more decentralized contexts local governments will provide to local residents public services more efficiently and more adherent to citizens' preferences. In addition, the strong theoretical argument in favour of regional autonomy put forward by political economy theorizing on decentralization is that it will improve the accountability and responsiveness of the local governments (Faguet, 2014; Weingast, 2014). As Serrano and Rodriguez-Pose (2011) put it, the primary aim of decentralization has never been about delivering greater economic growth, lowing inequality or increasing social capital; rather, "the original aim of decentralization is fundamentally to improve the delivering of public goods and services to individuals and, consequently, the level of satisfaction of the population with government" (p. 2, our emphasis). As the authors argue, this argument has been largely overlooked by the literature.

Another problem related to country-level analysis is that it tends to overlook the presence of heterogeneity both in the quality of local public services and in the degree of regional autonomy within the countries. Concerning the former, as we will show, the variability within country is not negligible, and in some cases it is substantial (Charron et al., 2014). Concerning the degree of regional autonomy, some countries are characterized by asymmetric federalism in that they exhibit differences in the degree of autonomy of their sub-national governments (Congleton et al., 2003). Also in these cases within country differences are quite sizeable. For instance, in Spain, specific arrangements have been made for Navarra and Basque communities regarding financial autonomy, while Galicia and Catalonia have special authority over education, language and culture; in the United Kingdom, Scotland and Wales are also more autonomous, and the Scottish Parliament has significant more autonomy in policy making than the Welsh Parliament; other examples are the presence of a few autonomous regions with stronger autonomy in Italy and Portugal.

Our second contribution lies in the empirical method employed. We employ a novel dose-response approach whose merit is that of overcoming some limits of traditional regression models (Cerulli, 2015a). In particular, dose-response models: (1) allow for going beyond the (single) average effect by providing an estimation of the effect in the form of a function (i.e., the dose-response function) defined along the values taken by the dose variable; (2) offer a clear-cut and easy-to-read graphical representation of results based on the plot of the dose-response function, thus making clearer the pattern of the causal link under analysis; (3) allow to study the entire distribution of the causal effect, thereby providing grounds for a more precise understanding of the observed pattern of the treatment effect.

An important issue is that of measuring the quality of local public services and the level of regional autonomy. In order to measure the former at the regional level we employ a composite indicator developed by The QOG Institute based on the citizens' perception about local public services (Quality of Government Institute, 2010; Charron and Lapuente, 2011). As far as the level of regional autonomy is concerned, we employ the Regional Authority Index developed by Hooghe et al. (2008a); these two indicators have a number of strengths and have been increasingly employed in this type of studies (e.g. Charron et al., 2014; Ezcurra and Rodríguez-Pose, 2012).

The rest of the paper is organized as follows. Next section presents our key measures, while Section three introduces our empirical strategy. Section four presents and discusses the results; Section five finally concludes. 


\section{Data: measuring the quality of local public services and the level of regional autonomy}

\section{The quality of local public services}

Several empirical studies have employed indirect measures of government quality, such as for instance outcomes in education or public works, public deficit, the degree of corruption, infant mortality (e.g. Bardhan and Mookherjee, 2006; Enikolopov and Zhuravskaya, 2007; Faguet, 2014; Fisman and Gatti, 2002). Several others have instead used the WGI Indicator developed by the World Bank (Kaufmann et al., 2011), which assesses the citizens' perception of government effectiveness, regulatory quality, rule of law, and control of corruption (e.g. Bartolini and Santolini, 2012; Kyriacou and Roca-Sagalés, 2011; O'Dwyer and Ziblatt, 2006). In line with this approach we employ a measure of the quality of local public services provided by the Quality of Government Survey (Charron et al., 2014; Quality of Government Institute, 2010) based on the citizens' perception of three local public services: education, health and law enforcement. ${ }^{3}$ These are also those public services that are usually investigated in decentralization studies (Sacchi and Salotti, 2014).

The indicator - regqog - is a perception-based indicator built from a 34,000-respondents survey from 172 regions within $18 \mathrm{EU}$ member states; to date, this constitutes one of the most comprehensive surveys about the quality of local public goods at the sub-national level. ${ }^{4}$ The survey was undertaken between 15 December, 2009, and 1 February, 2010 and consisted of 34 questions to the approximately 200 respondents per region. Respondents were asked about three general public services in their regions - education, health care and law enforcement. In focusing on these three services, respondents were asked to rate their public services with respect to three related concepts, namely the quality, impartiality and an inverse measure of the level of corruption of these services (the complete questionnaire can be found in the Appendix of Quality of Government Institute, 2010). The Survey also provides a single QoG index for each region obtained by averaging the three pillars - quality, impartiality and (lack of) corruption, each weighted $1 / 3^{\text {rd }}$. In our analysis we are going to use both the overall qog index performance as well as the three pillars. ${ }^{5}$ The data have been standardized such that the EU regional mean is ' 0 ' and has a standard deviation of ' 1 '. A series of extensive sensitivity tests to see whether changes in the model alter the final data was done. It arises that "data constructed here are highly robust to multiple changes in weighting and aggregation schemes, the removal of individual questions or alterations in the demographic makeup of the respondents" (Quality of Government Institute, 2010).

The Report suggests the presence of significant within-country variation from country to country (see Figure 1). As explained by Charron and Lapuente (2011) the data show that the indicator of QoG is either equally or more important than variation between EU countries themselves. For example, some regions in Italy and Belgium perform like those in the best performing countries, while others

\footnotetext{
${ }^{3}$ We want to thank Nicolas Charron and Victor Lapuente of 'The QOG Institute' of the University of Goteborg for their assistance with data issues. See also Charron, Nicholas, Stefan Dahlberg, Sören Holmberg, Bo Rothstein, Anna Khomenko \& Richard Svensson. 2016. The Quality of Government EU Regional Dataset, version Sep16. University of Gothenburg: The Quality of Government Institute, http://www.qog.pol.gu.se.

${ }^{4}$ Note that the authors call this index "quality of government index" since they use the provision of local public goods as a proxy for the quality of regional government. Our focus here is instead on the quality of local public services themselves, exploiting the heterogeneity in their organizational structure across regions.

${ }^{5}$ In the paper we will refer to overall performance to refer to the overall index, and to quality to refer to the single pillar 'quality'.
} 
rank similarly to low-performing regions in Hungary and Greece. This reinforces the need of going beyond national level when analysing this issue.

[Figure 1 about here]

The second point that is worth noting is the connection of regional QoG and regional autonomy. The level of regional variation within the country is not highly correlated to the degree of regional autonomy. It is easy to check that there is large variation within highly centralized countries (Portugal) as well as in highly decentralized countries (Belgium). Conversely, one can also observe low variation in the regqog index both in centralized countries (Denmark) and decentralized ones (Germany).

\section{The degree of regional autonomy}

Measuring decentralization is also not that straightforward. Most of the studies use the share of subnational revenues (or expenditures) on total revenues (expenditure) as a proxy for the degree of decentralization, namely fiscal decentralization. There are a number of problems associated to these measures since they tends to overestimate the degree of fiscal autonomy (Stegarescu, 2005). In addition, they disregard the multifaceted nature of decentralization in that they take into account only the financial dimension, while in fact countries' functioning in terms of distribution of power, responsibility, and resources among different tiers of government is defined also by administrative and political decentralization (Sacchi and Salotti, 2014).

In order to take these problems into account, we employ a comprehensive measure of regional autonomy, the Regional Authority Index (RAl) (Hooghe et al., 2008; Marks et al., 2008), which includes fiscal, political, and administrative measures of the authority of a regional government. This index has been used in these types of studies replacing measures of fiscal expenditures as proxy of decentralization (e.g. Ezcurra and Rodríguez-Pose, 2012; Rodríguez-Pose and Ezcurra, 2011). The Regional Authority Index - rai - measures the authority of regional governments in 42 democracies or quasi-democracies on an annual basis over the period 1950-2006. The countries included are twenty-nine OECD countries, the 27 countries that are members of the European Union, plus Albania, Bosnia and Herzegovina, Croatia, Macedonia, Russia, and Serbia and Montenegro.

The rai is formed by two components, which capture respectively the degree of authority exerted by a regional government over its territory (self-rule) and over the whole country (shared-rule). Self-rule regards the degree of independence of the regional government from the influence of central authorities and the scope of regional decision-making. In turn, shared-rule measures the capacity of the regional government to determine central decision-making. It is worth stressing that despite the name of the indicator, the rai refers not only to administrative decentralization but it also encompasses measures of political and fiscal decentralization. As such, it is possibly the most comprehensive indicator of regional autonomy that has been so far developed.

In figure 2 we plot the degree of regional autonomy and sub-national variation as an average over the period 2000-2006. ${ }^{6}$ Large differences in the degree of regional autonomy arise between

\footnotetext{
${ }^{6}$ In our analysis we would use the average level of 2000-2006. In fact, the rai variable changes extremely slowly over time, so that there are negligible variations over the last decade. This makes the results of our estimations robust to different values of the rai index over time. We also test our models by using earlier values of rai with no significant changes in the results.
} 
European countries, in particular federal-types countries such as Austria, Belgium, and Germany stand out with high figures. As for sub-national variation, a quite mixed picture emerges. Several countries show no variation, while others show moderate variation (e.g. Belgium, Spain, and Italy), as well as high variation (e.g. Portugal and United Kingdom).

[Figure 2 about here]

\section{Methodology}

In this paper, we are interested in studying the causal effect of regional autonomy (rai) on the overall performance of local public goods (regqog). To this purpose, we rely on the econometric literature on treatment effects estimation (Imbens and Wooldridge, 2009), and more specifically on that estimating dose-response models (Bia and Mattei, 2008; Cerulli, 2015a; Guardabascio and Ventura, 2013; Hirano and Imbens, 2004; Adorno et al., 2007). Dose-response models are well suited in socio-economic contexts where a "cause" takes the form of a continuous exposure to a certain treatment.

In such a setting what matters is not only the binary treatment status of observations (i.e., treated vs. untreated), but also the level of exposure (or "dose") undergone. This is also in tune with the language of epidemiology, where dose-response functions are usually estimated in order to check patients' resilience to different levels of drug administration (Royston et al., 2010).

Dose-response models have relevant advantages compared to traditional regression models: (1) they allow for going beyond the (single) average effect, by providing an estimation of the effect in the form of a function (i.e., the dose-response function) defined along the values taken by the dose variable; (2) they offer a clear-cut and easy-to-read graphical representation of results based on the plot of the dose-response function, thus making more clear the pattern of the causal link under analysis; (3) they allow to study the entire distribution of the causal effect, thereby providing grounds for a more precise understanding of the observed pattern of the treatment effect; (4) finally, they are embedded in a counterfactual design, lending to results a more reliable causal interpretation?

In this paper we are interested in estimating the causal effect of the dose variable rai on an outcome regqog $\mathrm{y}$, by assuming that units may respond differently both to specific observable confounders (that we collect in a vector $\mathrm{x}$ ), and to the "intensity" of the treatment rai. We wish to estimate a dose-response function of regqog on rai, when the treatment is assumed to be conditionally exogenous, namely, when selection-into-treatment depends only on observable-to-analyst factors.

We briefly present the model by setting out with some notation. This part draws on the econometric model developed by Cerulli (2015), which also includes a Stata 14 implementation via the userwritten command ctreatreg. Consider two different and exclusive outcomes: one referring to a unit $i$ when it is treated, $y_{1 i}$; and one referring to the same unit when it is untreated, $y_{0 i}$. Define $w_{i}$ as the treatment indicator, taking value 1 for treated and 0 for untreated units, and $\mathbf{x}_{i}=\left(x_{1 i}, x_{2 i}, x_{3 i}, \ldots\right.$,

\footnotetext{
7 In this application of the model all units are treated. However, rescaling the treatment variable to vary between zero and one naturally leads to identify units with zero treatment. This does not create problems, as in a continuous treatment setting, each treatment level rely on many counterfactuals, i.e. one for each level taken by the continuous treatment variable. In this sense, the zero treatment is in this case just one of many counterfactual states in which a given unit is placed.
} 
$x_{M i}$ ) as a row vector of $M$ exogenous and observable characteristics (confounders) for unit $i=1, \ldots$, $N$. Let $N$ be the number of units involved in the experiment, $N_{1}$ be the number of treated units, and $N_{0}$ the number of untreated units with $N=N_{1}+N_{0}$.

Define two distinct functions, $g_{1}\left(\mathbf{x}_{i}\right)$ and $g_{0}\left(\mathbf{x}_{i}\right)$, as the unit $i$ 's responses to the vector of confounding variables $\mathbf{x}_{i}$ when the unit is treated and untreated respectively. Assume $\mu_{1}$ and $\mu_{0}$ to be two scalars, and $e_{1}$ and $e_{0}$ two random variables having zero unconditional mean and constant variance. Finally, define $t_{i}$ - taking values within the continuous range $[0 ; 100]$ - as the continuous-treatment indicator, and $h\left(t_{i}\right)$ as a general derivable function of $t_{i}$. In what follows, in order to simplify notation, we'll get rid of the subscript $i$ when defining population quantities and relations.

Given previous notation, we assume a specific population generating process for the two exclusive potential outcomes:

$$
\begin{cases}w=1: & y_{1}=\mu_{1}+g_{1}(\mathbf{x})+h(t)+e_{1} \\ w=0: & y_{0}=\mu_{0}+g_{0}(\mathbf{x})+e_{0}\end{cases}
$$

where the $h(t)$ function is different from zero only in the treated status. Given this, we can also define the causal parameters of interests. Indeed, by defining the treatment effect as the difference $\mathrm{TE}=\left(y_{1}-y_{0}\right)$, we can define the causal parameters of interests as the population Average Treatment Effects (ATEs) conditional on $\mathbf{x}$ and $t$, that is:

$$
\begin{aligned}
& \operatorname{ATE}(\mathbf{x} ; t)=\mathrm{E}\left(y_{1}-y_{0} \mid \mathbf{x}, t\right) \\
& \operatorname{ATET}(\mathbf{x} ; t>0)=\mathrm{E}\left(y_{1}-y_{0} \mid \mathbf{x}, t>0\right) \\
& \operatorname{ATENT}(\mathbf{x} ; t=0)=\mathrm{E}\left(y_{1}-y_{0} \mid \mathbf{x}, t=0\right)
\end{aligned}
$$

where ATE indicates the overall average treatment effect, ATET the average treatment effect on treated, and ATENT the one on untreated units. By the law of iterated expectation (LIE), we know that the population unconditional ATEs are obtained as:

$$
\begin{aligned}
& \operatorname{ATE}=\mathrm{E}_{(\mathbf{x} ; t)}\{\operatorname{ATE}(\mathbf{x} ; t)\} \\
& \operatorname{ATET}=\mathrm{E}_{(\mathbf{x} ; t>0)}\{\operatorname{ATE}(\mathbf{x} ; t>0)\} \\
& \operatorname{ATENT}=\mathrm{E}_{(\mathbf{x} ; t=0)}\{\operatorname{ATE}(\mathbf{x} ; t=0)\}
\end{aligned}
$$

\footnotetext{
${ }^{8}$ Such a model is the representation of a treatment random coefficient regression as showed by Wooldridge (1997; 2003). See also Wooldridge (2010, Ch. 18).
} 
where $E_{\mathbf{z}}(\cdot)$ identifies the mean operator taken over the support of a generic vector of variables $\mathbf{z}$. By assuming a linear-in-parameters form for $g_{0}(\mathbf{x})=\mathbf{x} \boldsymbol{\delta}_{\mathbf{0}}$ and $g_{1}(\mathbf{x})=\mathbf{x} \boldsymbol{\delta}_{1}$, the Average Treatment Effect (ATE) conditional on $\mathbf{x}$ and $t$ becomes:

$$
\operatorname{ATE}(\mathbf{x}, t, w)=w \cdot[\mu+\mathbf{x} \boldsymbol{\delta}+h(t)]+(1-w) \cdot[\mu+\mathbf{x} \boldsymbol{\delta}]
$$

where $\mu=\left(\mu_{1}-\mu_{0}\right), \delta=\left(\delta_{1}-\delta_{0}\right)$, and the unconditional Average Treatment Effect (ATE) related to model $(1)$ is equal to:

$$
\operatorname{ATE}=p(w=1) \cdot\left(\mu+\overline{\mathbf{x}}_{t>0} \boldsymbol{\delta}+\bar{h}_{t>0}\right)+p(w=0) \cdot\left(\mu+\overline{\mathbf{x}}_{t=0} \boldsymbol{\delta}\right)
$$

where $p(\cdot)$ is a probability, and $\bar{h}_{t>0}$ is the average of the response function taken over $t>0$. Since, by LIE, we have that ATE $=p(w=1) \cdot A T E T+p(w=0) \cdot A T E N T$, we obtain from the previous formula that:

$$
\left\{\begin{array}{l}
\mathrm{ATE}=p(w=1)\left(\mu+\overline{\mathbf{x}}_{t>0} \boldsymbol{\delta}+\bar{h}_{t>0}\right)+p(w=0)\left(\mu+\overline{\mathbf{x}}_{t=0} \boldsymbol{\delta}\right) \\
\operatorname{ATET}=\mu+\overline{\mathbf{x}}_{t>0} \boldsymbol{\delta}+\bar{h}_{t>0} \\
\mathrm{ATENT}=\mu+\overline{\mathbf{x}}_{t=0} \boldsymbol{\delta}
\end{array}\right.
$$

where the dose-response function is given by averaging $\operatorname{ATE}(\mathbf{x}, t)$ over $\mathbf{x}$ :

$$
\operatorname{ATE}(t)=\left\{\begin{array}{lll}
\operatorname{ATET}+\left(h(t)-\bar{h}_{t>0}\right) & \text { if } & t>0 \\
\operatorname{ATENT} & \text { if } & t=0
\end{array}\right.
$$

that is a function of the treatment intensity $t$.

We consider the conditions for a consistent estimation of the causal parameters defined in (2) and (3) and thus of the dose-response function in (6). What it is firstly needed, however, is a consistent estimation of the parameters of the potential outcomes in (1) - we call here "basic" parameters - as both ATEs and the dose-response function are functions of these parameters. 
Under previous definitions and assumptions, and in particular the form of the potential outcomes in model (1), to be substituted into Rubin's potential outcome equation $y_{i}=y_{0 i}+w\left(y_{1 i}-y_{0 i}\right)$, the following baseline random-coefficient regression can be obtained (Wooldridge, 2003; Wooldridge, 1997):

$$
y_{i}=\mu_{0}+w_{i} \cdot \mathrm{ATE}+\mathbf{x}_{i} \boldsymbol{\delta}_{\mathbf{0}}+w_{i} \cdot\left(\mathbf{x}_{i}-\overline{\mathbf{x}}\right) \boldsymbol{\delta}+w_{i} \cdot\left(h\left(t_{i}\right)-\bar{h}\right)+\eta_{i}
$$

where

$$
\eta_{i}=e_{0 i}+w_{i} \cdot\left(e_{1 i}-e_{0 i}\right)
$$

The equation sets out in (12), provides the baseline regression for estimating the basic parameters $\left(\mu_{0}, \mu_{1}, \delta_{0}, \delta_{1}\right.$, ATE) and then all the remaining ATEs. Both a semi-parametric or a parametric approach can be employed as soon as a parametric or a non-parametric form of the function $h(t)$ is assumed. In both cases, however, in order to get a consistent estimation of basic parameters, we need some additional hypotheses. In this paper, we assume Unconfoundedness or Conditional Mean Independence (CMI), sufficient to provide parameters' consistent estimation. Unconfoundedness states that, conditional on the knowledge of the true exogenous confounders $\mathbf{x}$, the conditions for randomization are restored and causal parameters become identifiable. Given the set of random variables $\left\{y_{1 i}, y_{1 i}, w_{i}, \mathbf{x}_{i}\right\}$ as defined above, Unconfoundedness (or CMI) implies that:

$$
\mathrm{E}\left(y_{j i} \mid w_{i}, \mathbf{x}_{i}\right)=\mathrm{E}\left(y_{j i} \mid \mathbf{x}_{i}\right) \text { with } j=\{0,1\}
$$

CMI is a sufficient condition for identifying ATEs and the dose-response function in this context. Indeed, this assumption entails that, given the observable variables collected in $\mathbf{x}$, both $w$ and $t$ are exogenous in equation (7), so that we can write the regression line of the response $y$ simply as:

$$
\mathrm{E}\left(y_{i} \mid w_{i}, t_{i}, \mathbf{x}_{i}\right)=\mu_{0}+w_{i} \cdot \mathrm{ATE}+\mathbf{x}_{i} \boldsymbol{\delta}_{\mathbf{0}}+w_{i} \cdot\left(\mathbf{x}_{i}-\overline{\mathbf{x}}\right) \boldsymbol{\delta}+w_{i} \cdot\left(h\left(t_{i}\right)-\bar{h}\right)
$$

and Ordinary Least Squares (OLS) can be used to retrieve consistent estimation of all parameters. Once a consistent estimation of the parameters in (8) is obtained, we can estimate ATE directly from this regression, and ATET, ATENT and the dose-response function by plugging the estimated basic parameters into formula (5) and (6). This is possible because these parameters are functions of 
consistent estimates, and thus consistent themselves. Observe that standard errors for ATET and ATENT can be correctly obtained via bootstrapping (Wooldridge, 2010, pp. 911-919).

To complete the identification of ATEs and that of the dose-response function, we finally assume a parametric form for $h(t)$ :

$$
h\left(t_{i}\right)=a t_{i}+b t_{i}^{2}+c t_{i}^{3}
$$

where $a, b$, and $c$ are parameters to be estimated in regression (8).

Under CMI, an OLS estimation of equation (8) produces consistent estimates of the parameters, we indicate as $\hat{\mu}_{0}, \hat{\boldsymbol{\delta}}_{\mathbf{0}}, \mathrm{A} \hat{\mathrm{TE}}, \hat{\boldsymbol{\delta}}, \hat{a}, \hat{b}, \hat{c}$. With these parameters at hand, we can finally estimate consistently the dose-response function as:

$$
\hat{\operatorname{ATE}}\left(t_{i}\right)=w\left[\hat{\mathrm{ATET}}+\hat{a}\left(t_{i}-\frac{1}{N} \sum_{i=1}^{N} t_{i}\right)+\hat{b}\left(t_{i}^{2}-\frac{1}{N} \sum_{i=1}^{N} t_{i}^{2}\right)+\hat{c}\left(t_{i}^{3}-\frac{1}{N} \sum_{i=1}^{N} t_{i}^{3}\right)\right]+(1-w) \mathrm{ATENT}
$$

where:

$$
\hat{\operatorname{ATET}}\left(t_{i}\right)=\hat{\operatorname{ATE}}\left(t_{i}\right)_{t_{i}>0}
$$

A simple plot of the curve $\operatorname{ATE}\left(t_{i}\right)_{t_{i}>0}$ over the support of $t$ returns the pattern of the doseresponse function. Moreover, for each level of the dose $t$, it is also possible to calculate the $\alpha$ confidence interval around the dose-response curve. Indeed, by defining $T_{1}=t-E(t), T_{2}=t_{2}-E\left(t_{2}\right)$ and $T_{3}=$ $t_{3}-E\left(t_{3}\right)$, the standard error of the dose-response function is equal to ${ }^{9}$ :

$$
\hat{\sigma}_{\operatorname{ATE}(t)}=\left\{T_{1}^{2} \hat{\sigma}_{a}^{2}+T_{2}^{2} \hat{\sigma}_{b}^{2}+T_{3}^{2} \hat{\sigma}_{c}^{2}+2 T_{1} T_{2} \hat{\sigma}_{a, b}+2 T_{1} T_{3} \hat{\sigma}_{a, c}+2 T_{2} T_{3} \hat{\sigma}_{b, c}\right\}^{1 / 2}
$$

This means that the $\alpha$-confidence interval of $\operatorname{AT\hat {T}}(t)$ for each $t$ is then given by:

\footnotetext{
${ }^{9}$ This comes from the variance/covariance properties where $T_{1} T_{2} T_{3}$ are taken as constant and $a, b$ and $c$ as random variables.
} 


$$
\left\{\operatorname{ATEE}(t) \pm Z_{\alpha / 2} \cdot \hat{\sigma}_{\operatorname{ATE}(t)}\right\}
$$

that can be usefully plotted along the dose-response curve for detecting visually the statistical significance of the treatment effect along the support of the dose $t$.

\section{Results}

\section{Regional autonomy and the quality of local public services}

In this section we present the results of the dose-response analysis (see tables A1 and A2 in the Appendix for the list of variables and the correlation table). Table 1 reports the OLS robust estimates of equation (7). There are four models reported in the table, each corresponding to a different dependent variable. In the first model we employ the overall measure of performance of local public services, i.e. the regqog index, while in the second, third and fourth model we employ each of the pillars composing the index, which are respectively impartiality, lack of corruption, and quality of local services (health, education and the police force). Our key explanatory variable is the rai index which has been re-scaled to take values between 0 and $100 .{ }^{10}$

Several control variables, all at the region level, are included, namely: income per capita (here measured in PPP); three dummies variable controlling for i) bilingual region; ii) autonomous region; iii) capital region; the (log of) population and size (log of the area). Both bilingual regions and capital region variables are also meant to control for the presence of different ethnic minorities and migration inflows. These two factors, as discussed below, can play a role especially concerning the impartiality of local public services. A customary variable which is taken into account in political economy studies is the presence of strong and independent media, since they are considered an important channel through which citizens can keep the local policy makers under control. For this reason we have included the variable 'presence of independent media' which reflects "the strength and effectiveness of the media in the region to expose corruption" and is part of the same QOG Survey. We also include the variable "share of population with tertiary education" taken from Eurostat to control for the level of education of the regional population. On the one hand, higher level of education is expected to be positively correlated with the performance of local services because of a sorting effect, as a result of which better educated people tend to concentrate in areas with better services. On the other hand, the level of education can also affect the perception of the public services since better educated people can be more informed and more demanding. Therefore, the effect could be either positive or negative depending on the prevalence of the two effects. Finally, a variable taking into account the diverse composition of the population - a diversity

\footnotetext{
${ }^{10}$ The pairwise correlation between the qog index and its three pillars is reported in Table A3 in the Appendix. We have performed the Variance Inflation Factor (VIF) test to detect the presence of multicollinearity. The results are reported in Table A5 in the Appendix which show no concerns about multicollinearity, being all VIFs smaller than 10 . We have also performed a country fixed effects, obtained by introducing a dummy variable for each country; by excluding the country fixed effects from our baseline model as in column 1, we lose approximately around $23 \%$ of the total variance of our dependent variable explained by the country fixedeffect model.
} 
index - was included, in order to take into account the fact that the regional segregation of ethnic or linguistic groups is expected to lead to lower government quality (Alesina and Zhuravskaya, 2011; Kyriacou, 2012). Following the approach developed by Ozgen et al. (2011) our diversity index is calculated as follows: (1 - Herfindal index of nationality shares). Based on the census of $2011,{ }^{11}$ the index considers three types of population: native citizens, foreign EU residents, and foreign non-EU residents. ${ }^{12}$ As expected our diversity index shows regions such as London, Brussels and Vienna as those with the higher scores, and regions from Romania and Poland as those with lowest scores.

In this kind of setting spatial correlation can play an important role. A calculation of the Moran index reveals the presence of a positive spatial correlation in the performance of local public services, with an index equal to 0.853 , significant at 0.01 per cent (see Table A4 in the Appendix). In order to control for spatial correlation effects, we have introduced the variable contiguity spillover which is built as a contiguity matrix weighted for the rai index. More precisely, it represents the average value of the rai index of the regions that are contiguous to the region $I$, and belong to the same country. The reason for introducing this variable is grounded on a prominent argument of fiscal decentralization theory, which is the role of horizontal competition among local governments. In brief, the idea is that one of the important side-effects of decentralization is that it encourages virtuous competition among neighbours' regional governments. If citizens (and companies) can 'vote with their feet' they would be inclined to move to regions that are better governed, i.e. where public services are better provided (Besley and Case, 1995; Bordignon et al., 2003; Binet, 2003). In fact, citizens tend to judge their politicians not only by looking at their absolute performance but also by comparing their performance to those of neighbours' politicians that they can easily observe. According to these arguments, in a more decentralized settings horizontal competition among regional government should improve policy makers' incentives in providing good local public goods. We therefore expect the related coefficient to show a positive sign.

Finally, we introduce two control variables at the country level. Firstly, a dummy variable for regions belonging to EU-15 Member countries is introduced. Secondly, the quality of local public services can also depend on the actual amount of resources which are available to regional governments, other than their level of autonomy. In order to take this into account, we introduce a standard measure of tax decentralization, measured as the share of sub-central governments' own tax revenues on general government total tax revenues (as in Filippetti and Sacchi, 2016).

The results in Table 1 across the four models suggest, as expected, a positive impact of per capita income on the overall performance of regional governments, as well as on the three pillars of the index. Being a bilingual region is negatively associated to corruption and quality of public services. Capital region is negatively correlated with public services across the all models, but significant only for corruption; this possibly depending on congestion effects and the presence of most national governments' offices in these regions. A similar effect can also justify the negative effect of population, and, for opposite reasons, the positive effect of the size. The presence of strong and independent media in the region is positively correlated with the quality of local public service (model 4). The share of population with tertiary education arises as negatively associated with public services, especially overall performance and corruption. We can interpret this result considering that

\footnotetext{
${ }^{11}$ Data can be found here: https://ec.europa.eu/CensusHub2/query.do?step=selectHyperCube\&qhc=false.

12 Note that adding up the share of "stateless" population leaves the index virtually unchanged.
} 
the sorting effect is already captured by per capita income, and therefore the negative association with the provision of public services of well-educated people might depend on the fact the latter tend to be more demanding and better informed. As expected, and in line with empirical evidence mentioned above, our diversity index suggests that more diverse environments are associated with lower perceived quality of the provision of public services, possibly depending to the negative effect of segregation on inter-group trust (Kyriacou, 2012). Finally, the variable country tax decentralization is positively correlated in the first three models, but negatively with the quality of local services.

Regarding the correlation between regional autonomy and the four dependent variables, the binary autonomy treatment is negative and highly significant in the first and in the third model, thus suggesting a negative correlation between regional autonomy and the overall performance of local public services and corruption. Our binary treatment variable is a dummy taking 1 for all the regions, except those exhibiting the lowest score of regional autonomy (taking 0 ), that in our sample are mainly Bulgarian and Portuguese regions. As a result, the obtained value of ATE should not be strictly interpreted as a general counterfactual result. This is not a serious limitation nonetheless, as our main goal is to focus on the pattern of our dependent variable along a continuous scale of regional autonomy, i.e. ATE $(t)$, which is independent of the value at $t=0$ where our binary treatment is zero too.

The effect of regional autonomy on local public goods along a continuous scale is reported in the charts in Figure 3, each corresponding to a model in Table 1. The four charts display the doseresponse functions, which are the patterns of the impact of the treatment - regional autonomy - on our indicator of overall performance of regional governments and its three pillars. For each model, estimations in Table 1 report both each single polynomial coefficient ( $T w \_1, T w \_2$, and Tw_3) as well as the join test of their significance in order to accept or reject the shape of the dose-response function as depicted in the charts. The tests suggest that we can accept the shape of the distribution for all models except that for model 3 relative to corruption. ${ }^{13}$

The chart relative to overall performance of local public services - the reggog index - exhibits a ushaped form. This seems to suggest that in regions with either low autonomy or high autonomy, citizens' satisfaction in the provision of local public services surges. By contrast, the central area, where the level of regional autonomy is moderate exhibits a negative association with the performance of local public services. The second chart reports the dose-response function for the pillar impartiality. ${ }^{14}$ The distribution suggests a high level of impartiality for less autonomous regions, a low level in the middle and then again a rise in the level of impartiality; for values higher than 80 the estimation is no longer significant. In fact, in this curve there are several areas in which

\footnotetext{
${ }^{13}$ Observe that it is perfectly possible either that single coefficients significance tests accept the null for each coefficient, while the joint test of significance leads to reject equality to zero, or vice versa. Indeed, the single parameters combined confidence region (bases on T-students) is a rectangular area, whereas the joint-test confidence region (based on the F-test) is an ellipse. Therefore, they do not overlap perfectly.

${ }^{14}$ It is important to recall here how the concept of impartiality is captured by the index. The study takes two complementary approaches. With a first set of questions, citizens are asked to rate whether they agreed that 'certain people' get special advantages when dealing with the public service in question from 0 (strongly disagree) to 10 (strongly agree). With a second set of questions citizens are asked whether all people in their region are 'treated equally' by the service in question on a four point scale (Agree, rather agree, rather disagree or Disagree); for details see (Quality of Government Institute, 2010).
} 
the upper and lower bounding curves cross the 0 , therefore the shape should be interpreted with caution.

The third chart displays the dose-response function of regional autonomy on an inverse measure of corruption. In this case we observe a clear negative pattern; in fact, the joint tests reported in Table 1 suggest this distribution to be a straight line. This entails that a higher level of regional autonomy is negatively correlated with the performance of local public services in terms of corruption. Results on the impact of decentralization on corruption are quite mixed (Fisman and Gatti, 2002; Lederman et al., 2005). On the one hand it is argued that decentralization, by improving the accountability of policy makers, reduces the incentives for corruption. On the other hand, local politicians can be more prone to be captured by local groups of interests. Our results are moderately consistent with this latter view.

The fourth chart is related to the perceived quality of local public services. A u-shaped arises suggesting high quality in the provision of local public services both for less autonomous regions and for highly autonomous regions. It should be noted that the left-side and right-side extremes are not statistically significant. In principle, the area which is statistically significant is that between 45 and 80. Having said that, we can cautiously posit that this result is consistent with both the view regarding the relationship between the quality of local public good and regional autonomy. On the one hand, better performance the quality of local public good of centralized institutional settings is argued to derive from by the presence of spillover effects and economies of scale, and the need for central coordination. On the other hand, standard arguments in favour of decentralization argue that governments closer to the citizens will provide public services which are closer to the preferences of citizens. Importantly, our evidence points to a lower quality of local public services associated to middle-range levels of regional autonomy.

[Table 1 about here]

[Figure 3 about here]

Summing up, in this section we have highlighted two important results about the relationship between regional autonomy and local public services. Firstly, we have not detected the presence of one optimal level or area of regional autonomy for good governments, since the relationship between regional autonomy and the overall performance of local public services is not monotonic: both low regional autonomy and high regional autonomy are associated to higher levels of performance of local public services. Secondly, by looking at all the charts together one can observe that the regions that are in a middle ground area perform systematically poorer: this suggests the presence of a sort of 'no man's land' where neither the benefits of centralization nor the benefits decentralization are fully internalized.

The presence of a u-shaped relationship between regional authority and the performance of local public services can be interpreted by relying on two main arguments. One is the classic problem of the division of competences between the different levels of government in multi-level institutional environments. Our results suggest that both unitary institutional settings and highly-decentralized institutional settings are more effective in solving the several conflicts (or agency problems) that might arise between central and regional governments (Besley and Coate, 2003; Bird, 1993). The bad performance of regions characterized by average levels of regional authority can be explained as a 
consequence of overlapping competences that generate conflicts between different levels of government, which are likely to arise especially when fiscal federalism is pursued without establishing a clear division of political and administrative competences among them.

This is the case for instance for the so-called concurrent competences between the central government and the regions. A case in point is the decentralization reform introduced in Italy in 2001, whereas the fiscal federalism associated with a lack of devolution of clear competences to regional governments and the presence of several concurrent competences have generated major conflicts between regional and central government policy making. Since the introduction of the reform up to 2014 some 871 regional laws have been brought by the central government to the Constitutional Court. This has severely impaired the efficient functioning of the reform, and, as a consequence, on many of these issues the current government is bringing back competences from the regions to the central government. France is another case in point. Apart from the regions and departments, France has some 36,777 municipalities, some included into the 2,500 intercommunal grouping, while the central government is represented by 100 local prefectures and more than 200 sub-prefectures. This structure is often referred to as an administrative "mille-feuille (thousandlayer) cake". ${ }^{15}$ This has led to multiple overlapping of functions in several areas which is often considered as a major obstacle to efficiency of local governments (Carnegy, 2014).

The problem of overlapping competence among several layers of government can be exacerbated by a lack of political decentralization. A lack of political responsibility might facilitate capture by local lobbies (Blanchard and Shleifer, 2000), while strong political accountability favor greater accountability and responsiveness of local governments (Faguet, 2004) and public policies that are more suited to local heterogeneous preferences (Bird, 1993). This depends on the fact that in the case of strong political decentralization, politicians face a set of strong incentives that are aligned to the incentives of the citizens. In cases of partial decentralization, when both the central and the local governments share the responsibility for the provision of some local public services, several issues can make the functioning of the institutional system inefficient. In these cases the ability of voters to keep politicians in check is limited. Further, partial decentralization can give raise to vertical strategic interaction between the different levels of governments (Joanis, 2014). In fact, the problem of shared responsibility and its consequence on political accountability has been recognized to play a relevant role in explaining several cases in which decentralization reforms have led to a disappointing outcome (Bardhan and Mookherjee, 2006; Khemani, 2010).

By looking at the overall picture, countries seem to be confronted with two different options in terms of the distribution of political power and fiscal autonomy among their levels of governments which are both conducive to good local public services provision. This is consistent with a lack of convergence in the degree of decentralization that we can observe across countries. Even though a general trend towards decentralization has taken place over the past decades, significant difference are still present. In fact, one can see countries characterized by good performance of local public services provision but showing at the same time sizeable difference along the degree of decentralisation, such as federal states like Austria and Germany on the one hand, and the Scandinavian countries on the other hand.

${ }^{15}$ We are indebted with Marc Graham for this insight. 


\section{Three robustness exercises}

A possible problem with our data is that of comparing regions which differ remarkably, namely those belonging to the EU-15 countries and those belonging to the New Member countries from the Eastern European countries. A part from the stage of development (which we were able to control for by using the levels of per capita income), it should be noted that the local governments in New Member countries are still in their infancy, although the European cohesion policy has encouraged their active role within the multi-level governance framework (Hooghe and Marks, 2001). This is also reflected in their low level of regional autonomy. For these reasons we have repeated the same exercise restricting the sample to the $126 \mathrm{EU}-15$ regions (the regressions reported in Table 6A in the Appendix).

Figure 4 reports the charts corresponding to each of the model estimates in Table 6A. In this case, all the joint tests of significance on the polynomial coefficients reject the null hypothesis that they are jointly equal to zero. Therefore, these results are close to those obtained using the whole sample, with the shape of the plotted dose-response functions to be taken as satisfactorily reliable. The ushape arising from the first model is still present, and, if anything, even more clear cut. By looking at the impartiality of public good management, a similar shape arises, with two maximum at both low and high degree of autonomy. As in the previous case, a negative pattern for corruption arises. Also for the quality the curve looks similar, although now the area which is statistically significant is broader thus reinforcing the u-shape effect previously observed.

[Figure 4 about here]

A second robustness exercise addresses the different timing of decentralization reforms. In fact, countries in our sample have introduced decentralization in different times. Some have been federal states for several decades, such as Germany, while others have carried out decentralization reforms more recently, such as Italy and Spain. Therefore, it could be argued that there are differences in the quality of local public services that depends on the fact that some of them have developed a greater maturity in managing their autonomy, while others have not yet. This in turn can depend on the development of a more experienced local political class, on the need to adjust the whole administrative structure of States, as well as on the capacity of the citizens themselves to monitor and put pressure on local officers. In addition, this attempt to take into account reverses causality. It is possible that regions that are more developed and with more efficient institutions could ask for higher autonomy; this is indeed one of reasons why some rich regions, as for instance in Spain and Italy, have been claiming greater autonomy in the recent past. In order to control for this possible bias, we have run the same estimates as in Table 1 using earlier valued of rai, namely 1980 (we had to rely on 1990 values of rai for regions belonging to the Eastern European countries). The shapes of the distributions do not change significantly, so they are not reported here.

In the third robustness exercise we rely on the self-rule component of the rai index. In so doing we are going to focus on one dimension of regional autonomy, that concerning the degree of independence of the regional government from the influence of central authorities and the scope of regional decision-making; by contrast, we are instead not considering the capacity of the regional government to determine central decision-making, which is a typical feature of regional government in federal countries. 
Figure 5 below report charts corresponding to each of the model estimates in Table 7A. The results are remarkably different from those presented in Figure 3. All the curves exhibit a negative slope, suggesting a negative effect of increasing autonomy on the performance of public service and all its components. In fact, the correlation between the overall rai index and the self-rule index is equal to 0.84 , thus suggesting some non negligible difference between the two. By looking at the two indexes, one can observe that the regions scoring high on self-rule, and low - or moderately-low - on shared rule, are some regions in Spain and Italy. These countries do not have a proper federal constitution, although their institutional settings are regionalist. By contrast, regions from federal countries such as those in Germany and Belgium are those scoring high in shared-rule. Hence, one way to interpret our results is that the positive effect of regional autonomy that we can see in the curve in Figure 3, and that disappears in Figure 5, is driven by regions that retain high autonomy both in the self-rule and in the shared-rule indicators, that is those regions belonging to federal countries. Therefore, the capacity of the regional government to determine central decision-making seems to matter for improving the performance of public services. The lack (or weakness) of the institutional component of regional autonomy seems to play an important role in explaining the bad performance of autonomous regions in delivering public services.

[Figure 5 about here]

\section{Conclusion}

This paper tests a central prediction formulated by the theory of decentralization and fiscal federalism according to which more autonomous regional governments should perform better in the provisions of local public services. It attempts to inform this key issue by making two contributions. Firstly, it addresses this issue at the region level for the first time (to our knowledge). As said, this is a call coming from the theory itself: if the fiscal federalism theory is right, this should be reflected first and foremost in the provision of local public good and in the activity of local governments (DiazSerrano and Rodríguez-Pose, 2011). Secondly, it proposes a novel dose-response method which is employed in this context for the first time. Compared to traditional regression models, our method allows us to investigate the entire pattern of the effect of regional autonomy on the performance of local public services.

There are limitations that need to be discussed in some detail. In order to carry out the analysis at the region level we had to rely on the first measure of decentralization developed at the region level (the raireg index). This measure captures differences in the autonomy within countries which in several cases are significant. However, an important limitation of this measure is that in some countries there is no variation, since the regional governments have all the same level of autonomy; this occurs both in federal countries and unitary countries. As a result, the variation in the treatment variable is quite limited, while dose-response approaches would be more reliable with a greater variability in the treatment variable. Secondly, when analysing local phenomena, the role of spatial correlation can play an important role. In our case, the performance of a region can be affected by that of the neighbour's regional governments. Exploring this issue would have required a spatial autoregressive approach. Unfortunately, at this stage, this class of models cannot be implemented within our dose-response model. This is certainly an interesting methodological step forward, which could be worth developing. 
Third, limitations should be discussed also with regard to the identification assumptions our doseresponse model relies upon. The first and more relevant of them is the assumption of conditional mean independence at any dose level, which implies that, at each dose, no unobservable confounders (i.e., variables having a simultaneous effect on treatment level and outcome) are supposed to exist. Whenever unobservables are present, this may lead to OLS biased estimates though. This would require the use of an instrumental-variables (IV) approach, which is even more biased than OLS in small samples with weak instruments (Cerulli, 2015b, pp. 175-180). As our setting and information does not provide "natural" instruments able to induce exogenous variation on the treatment (the so-called 'intent-to-treatment'), we preferred to stick to OLS. In any case, our model specification includes a sufficiently large amount of meaningful control variables that - altogether should allow us to limiting estimation noise induced by the presence of unobservables. Another limitation of our model is that it relies on a parametric specification of the potential outcomes. We were obliged to go into this direction as - to our knowledge - comparable non-parametric doseresponse models have not been developed yet. As such, our approach can be included within the larger family of Regression Adjustment (RA) counterfactual methods, which are inherently parametric. The choice of interpolating a (global) polynomial function of the dose is however an attempt to relax at least the linearity of the model.

Finally, the availability of data covering a longer span of time would allow delving into the causality issue in a more appropriate way. Summing up, our findings should not be taken as definitive in the relationship between autonomy and good governance. Quite the contrary, this study intends to be exploratory, in that it shows the room for improving our understanding of much complex phenomena employing both a finer inspection within the countries, as well as approaches which go beyond average measures such as for instance is that case of the average treatment effect in doseresponse approaches.

Our evidence points to the presence of two areas of autonomy, corresponding to a highlycentralized setting and a highly-decentralized setting, which exhibit a better provision of local public services, at least according to the citizens' perception. This result militates against the presence of one ideal or optimal level of regional autonomy, and, consequently, against policy recommendations based on the view that more decentralization is always desirable. It is instead consistent with that stream of research in institutional economy and comparative political economy according to which different institutional settings can be economically viable and efficient (e.g. Hall and Soskice, 2001). To this regard, this result is also a stimulus for further theoretical developments in this area which take into account the idea of institutional coherence (Amable, 2000): both unitary and decentralized institutional setting can provide local public services efficiently if the whole institutional structure including the fiscal structure, the political responsibility, and the administrative organization - is properly designed accordingly.

Three main implications can be derived. Firstly, the lack of convergence towards decentralized systems across countries is justified by the fact that both centralized and decentralized systems can deliver good policies and good public services (for a similar finding in a different context see Hall and Gingerich, 2009). We find no absolute superiority of decentralized systems of governance, at least concerning the provisions of local public services. Secondly, we can conclude that placing themselves in an intermediate position seems to be worse than being located in one of the two extremes (high centralization, or high decentralization). As a result, if a country is willing to carry out a 
decentralization reform it should push this towards high levels of decentralization, avoiding being stuck in the middle of the road. Finally, our robustness analysis shows that the capacity of the regional government to determine central decision-makingis as much as important as the degree of independence of the regional government from the influence of central authorities and the scope of regional decision-making.

A final note concerns the role of decentralization in a context in which the pace of immigration is increasing and it is likely to play a greater role in the future European society. As a result, the populations of European regions are becoming more heterogeneous, thus putting more pressure for more tailor-made and impartiality in the provisions of public services. Our evidence seems to suggest that, as much as decentralization is an effective answer to the demand for impartiality in public policy, immigration is likely to be another bottom-up element of pressure for devolving greater autonomy to regional and local governments in Europe. Countries characterized by high heterogeneity in the population, as for instance in the case of the presence of ethnic minorities, might attach greater importance to the impartiality of public service provision to ensure social stability and avoid tensions among citizens belonging to different groups; here decentralization would be a good option. This is an interesting avenue for future research.

\section{Acknowledgments}

The authors would like to thank for their helpful comments and suggestions Agnese Sacchi, Raffaella Santolini, the members of the Research Group on Economic Policy Analysis "GRAPE" of Rome, and two anonymous reviewers. We would like to thank also the participants to the ERSA 54th Congress Saint Petersburg, Russia 26-29 August 2014. Andrea Filippetti gratefully acknowledges the Marie Curie Intra-European Fellowship project FP7-PEOPLE-2011-IEF-298167-REGIO_SPIN, under the EC Grant Agreement No: PIEF-GA-2011-298167. The authors are solely responsible for any errors contained in the paper. 


\section{References}

Adorno, V., Bernini, C. and Pellegrini, G. (2007) 'The Impact of Capital Subsidies: New Estimations under Continuous Treatment', Giornale degli economisti e annali di economia, 67-92.

Alesina, A. and Zhuravskaya, E. (2011) 'Segregation and the Quality of Government in a Cross Section of Countries', The American Economic Review, 101, 1872-1911.

Amable, B. (2000) 'Institutional Complementarity and Diversity of Social Systems of Innovation and Production', Review of International Political Economy, 7, 645-687.

Bache, I. and Jones, R. (2000) 'Has EU Regional Policy Empowered the Regions? A Study of Spain and the United Kingdom', Regional \& Federal Studies, 10, 1-20.

Bae, S., Jeong, M. and Moon, S. (2015) 'Effects of Institutional Arrangements in Local Water Supply Services in Korea', Papers in Regional Science, 94, 849-868.

Bardhan, P. and Mookherjee, D. (2006) 'Decentralisation and Accountability in Infrastructure Delivery in Developing Countries', The Economic Journal, 116, 101-127.

Bartolini, D. and Santolini, R. (2012) 'Regional Autonomy and the Quality of Governance in OECD Countries'.

Besley, T. and Case, A. (1995) 'Incumbent Behavior: Vote-Seeking, Tax-Setting, and Yardstick Competition', The American Economic Review, 25-45.

Besley, T. and Coate, S. (2003) 'Centralized versus Decentralized Provision of Local Public Goods: A Political Economy Approach', Journal of Public Economics, 87, 2611-2637.

Bia, M. and Mattei, A. (2008) 'A Stata Package for the Estimation of the Dose-response Function through Adjustment for the Generalized Propensity Score', The Stata Journal, 8, 354-373.

Binet, M.-E. (2003) 'Testing for Fiscal Competition among French Municipalities: Granger Causality Evidence in a Dynamic Panel Data Model', Papers in Regional Science, 82, 277-289.

Bird, R. M. (1993) 'Threading the Fiscal Labyrinth: Some Issues in Fiscal Decentralization', National Tax Journal, 207-227.

Blanchard, O. and Shleifer, A. (2000) Federalism with and without Political Centralization: China versus Russia, National Bureau of Economic Research.

Bordignon, M., Cerniglia, F. and Revelli, F. (2003) 'In Search of Yardstick Competition: A Spatial Analysis of Italian Municipality Property Tax Setting', Journal of Urban Economics, 54, 199217.

Brennan, G. and Buchanan, J. M. (1980) The Power to Tax: Analytic Foundations of a Fiscal Constitution, Cambridge University Press.

Breton, A. (2002) 'An Introduction to Decentralization Failure', Managing Fiscal Decentralization, 31-45.

Carnegy, H. (2014) 'Hollande Pledges Shake-up of France's Government "millefeuille"', Financial Times, June 3, 2014. Retrived at http://www.ft.com/cms/s/0/adffOb20-eb1a-11e3-9c8b00144feabdc0.htmI\#axzz3v8TQqjiQ (2014). 
Cerulli, G. (2015a) 'Ctreatreg: Command for Fitting Dose-Response Models under Exogenous and Endogenous Treatment', Stata Journal, 15, 1019-1045.

Cerulli, G. (2015b) Econometric Evaluation of Socio-Economic Programs: Theory and Applications, Springer, 49.

Charron, N., Dijkstra, L. and Lapuente, V. (2014) 'Regional Governance Matters: Quality of Government within European Union Member States', Regional Studies, 48, 68-90.

Charron, N. and Lapuente, V. (2011) 'Why Do Some Regions in Europe Have Higher Quality of Government?', QoG WORKING PAPER SERIES, 1.

Congleton, R. D., Kyriacou, A. and Bacaria, J. (2003) 'A Theory of Menu Federalism: Decentralization by Political Agreement', Constitutional Political Economy, 14, 167-190.

Diaz-Serrano, L. and Rodríguez-Pose, A. (2011) 'Decentralization, Happiness and the Perception of Institutions', IZA Discussion Paper No. 5647. Available at SSRN: http://ssrn.com/abstract=1812532.

Enikolopov, R. and Zhuravskaya, E. (2007) 'Decentralization and Political Institutions', Journal of Public Economics, 91, 2261-2290.

Ermini, B. and Santolini, R. (2014) 'Does Globalization Matter on Fiscal Decentralization? New Evidence from the OECD', Global Economic Review, 43, 153-183.

European Institute of Public Administration (EIPA) (2012) 'Division of Powers between the European Union, the Member States and Regional and Local Authorities'.

Ezcurra, R. and Rodríguez-Pose, A. (2012) 'Political Decentralization, Economic Growth and Regional Disparities in the OECD', Regional Studies, 1-14.

Faguet, J.-P. (2004) 'Does Decentralization Increase Government Responsiveness to Local Needs?: Evidence from Bolivia', Journal of Public Economics, 88, 867-893.

Faguet, J.-P. (2014) ‘Decentralization and Governance', World Development, 53, 2-13.

Filippetti, A. and Sacchi, A. (2016) 'Decentralization and Economic Growth Reconsidered: The Role of Regional Authority', Environment and Planning C: Government and Policy, 34, 1793-1824.

Fisman, R. and Gatti, R. (2002) 'Decentralization and Corruption: Evidence across Countries', Journal of Public Economics, 83, 325-345.

González-Alegre, J. (2015) 'Does Fiscal Decentralization Affect the Effectiveness of Intergovernmental Grants? European Regional Policy and Spanish Autonomous Regions', Papers in Regional Science, 94, 817-847.

Grassmueck, G. and Shields, M. (2010) 'Does Government Fragmentation Enhance or Hinder Metropolitan Economic Growth?', Papers in Regional Science, 89, 641-657.

Guardabascio, B. and Ventura, M. (2013) 'Estimating the Dose-Response Function through the GLM Approach', MPRA Paper No. 45013, March 2013. 
Hall, P. A. and Gingerich, D. W. (2009) 'Varieties of Capitalism and Institutional Complementarities in the Political Economy: An Empirical Analysis', British Journal of Political Science, 39, 449482.

Hall, P. A. and Soskice, D. (2001) Varieties of Capitalism: The Institutional Foundations of Comparative Advantage, Oxford, Oxford University Press.

Hayek, F. (1945) 'The Use of Knowledge in Society', American Economic Review, 35, 519-530.

Hirano, K. and Imbens, G. W. (2004) 'The Propensity Score with Continuous Treatments', Applied Bayesian modeling and causal inference from incomplete-data perspectives, 226164, 73-84.

Hooghe, L. and Marks, G. (2001) Multi-Level Governance and European Integration, Rowman \& Littlefield Pub Inc.

Hooghe, L., Marks, G. and Schakel, A. H. (2008) 'Operationalizing Regional Authority: A Coding Scheme for 42 Countries, 1950-2006', Regional and Federal Studies, 18, 123-142.

Imbens, G. W. and Wooldridge, J. M. (2009) 'Recent Developments in the Econometrics of Program Evaluation', Journal of Economic Literature, 47, 5-86.

Joanis, M. (2014) 'Shared Accountability and Partial Decentralization in Local Public Good Provision', Journal of Development Economics, 107, 28-37.

Kaufmann, D., Kraay, A. and Mastruzzi, M. (2011) 'The Worldwide Governance Indicators: Methodology and Analytical Issues', Hague Journal on the Rule of Law, 3, 220-246.

Khemani, S. (2010) 'Political Capture of Decentralization: Vote-Buying through Grants-Financed Local Jurisdictions', World Bank Policy Research Working Paper Series.

Kyriacou, A. P. (2012) 'Ethnic Segregation and the Quality of Government: The Importance of Regional Diversity', Constitutional Political Economy, 23, 166-180.

Kyriacou, A. P., Muinelo-Gallo, L. and Roca-Sagalés, O. (2015) 'Fiscal Decentralization and Regional Disparities: The Importance of Good Governance', Papers in Regional Science, 94, 89-107.

Kyriacou, A. P. and Roca-Sagalés, O. (2011) 'Fiscal Decentralization and Government Quality in the OECD', Economics Letters, 111, 191-193.

Lederman, D., Loayza, N. V. and Soares, R. R. (2005) 'Accountability and Corruption: Political Institutions Matter', Economics \& Politics, 17, 1-35.

Liberati, P. and Sacchi, A. (2013) 'Tax Decentralization and Local Government Size', Public Choice, 157, 183-205.

Marks, G., Hooghe, L. and Schakel, A. H. (2008) 'Measuring Regional Authority', Regional and Federal Studies, 18, 111-121.

Oates, W. E. (1972) Fiscal Federalism New York, Harcourt Brace Jonanovitch.

Oates, W. E. (2005) 'Toward a Second-Generation Theory of Fiscal Federalism', International Tax and Public Finance, 12, 349-373. 
O'Dwyer, C. and Ziblatt, D. (2006) 'Does Decentralisation Make Government More Efficient and Effective?', Commonwealth \& Comparative Politics, 44, 326-343.

Olson, M. (1993) 'Dictatorship, Democracy, and Development.', American Political Science Review, 87, 567-576.

Ozgen, C., Nijkamp, P. and Poot, J. (2011) 'Immigration and Innovation in European Regions'.

Quality of Government Institute (2010) Measuring the Quality of Government and Subnational Variation, Report for the European Commission Directorate-General Regional Policy Directorate Policy Development.

Rodríguez-Pose, A. and Ezcurra, R. (2011) 'Is Fiscal Decentralization Harmful for Economic Growth? Evidence from the OECD Countries', Journal of Economic Geography, 11, 619-643.

Rodriguez-Pose, A. and Sandall, R. (2008) 'From Identity to the Economy: Analysing the Evolution of the Decentralisation Discourse', Environment and Planning C: Government and Policy, 26, $54-72$.

Royston, P., Sauerbrei, W. and Becher, H. (2010) 'Modelling Continuous Exposures with a "spike"at Zero: A New Procedure Based on Fractional Polynomials', Statistics in medicine, 29, 12191227.

Sacchi, A. and Salotti, S. (2014) 'A Comprehensive Analysis of Expenditure Decentralization and of the Composition of Local Public Spending', Regional Studies, 50, 1-17.

Stegarescu, D. (2005) 'Public Sector Decentralisation: Measurement Concepts and Recent International Trends', Fiscal Studies, 26, 301-333.

Tanzi, V. (2001) Pitfalls on the Road to Fiscal Decentralization, Carnegie Endowment for International Peace.

Thornton, J. (2007) 'Fiscal Decentralization and Economic Growth Reconsidered', Journal of Urban Economics, 61, 64-70.

Tiebout, C. M. (1956) 'A Pure Theory of Local Expenditures', Journal of Political Economy, 64, 416424.

Treisman, D. (2007) The Architecture of Government: Rethinking Political Decentralization, Cambridge University Press Cambridge.

Weingast, B. R. (2014) 'Second Generation Fiscal Federalism: Political Aspects of Decentralization and Economic Development', World Development, 53, 14-25.

Wooldridge, J. M. (1997) 'On Two Stage Least Squares Estimation of the Average Treatment Effect in a Random Coefficient Model', Economics Letters, 56, 129-133.

Wooldridge, J. M. (2003) 'Further Results on Instrumental Variables Estimation of Average Treatment Effects in the Correlated Random Coefficient Model', Economics Letters, 79, 185191.

Wooldridge, J. M. (2010) Econometric Analysis of Cross Section and Panel Data, MIT press. 


\section{Tables and Figures for the text}

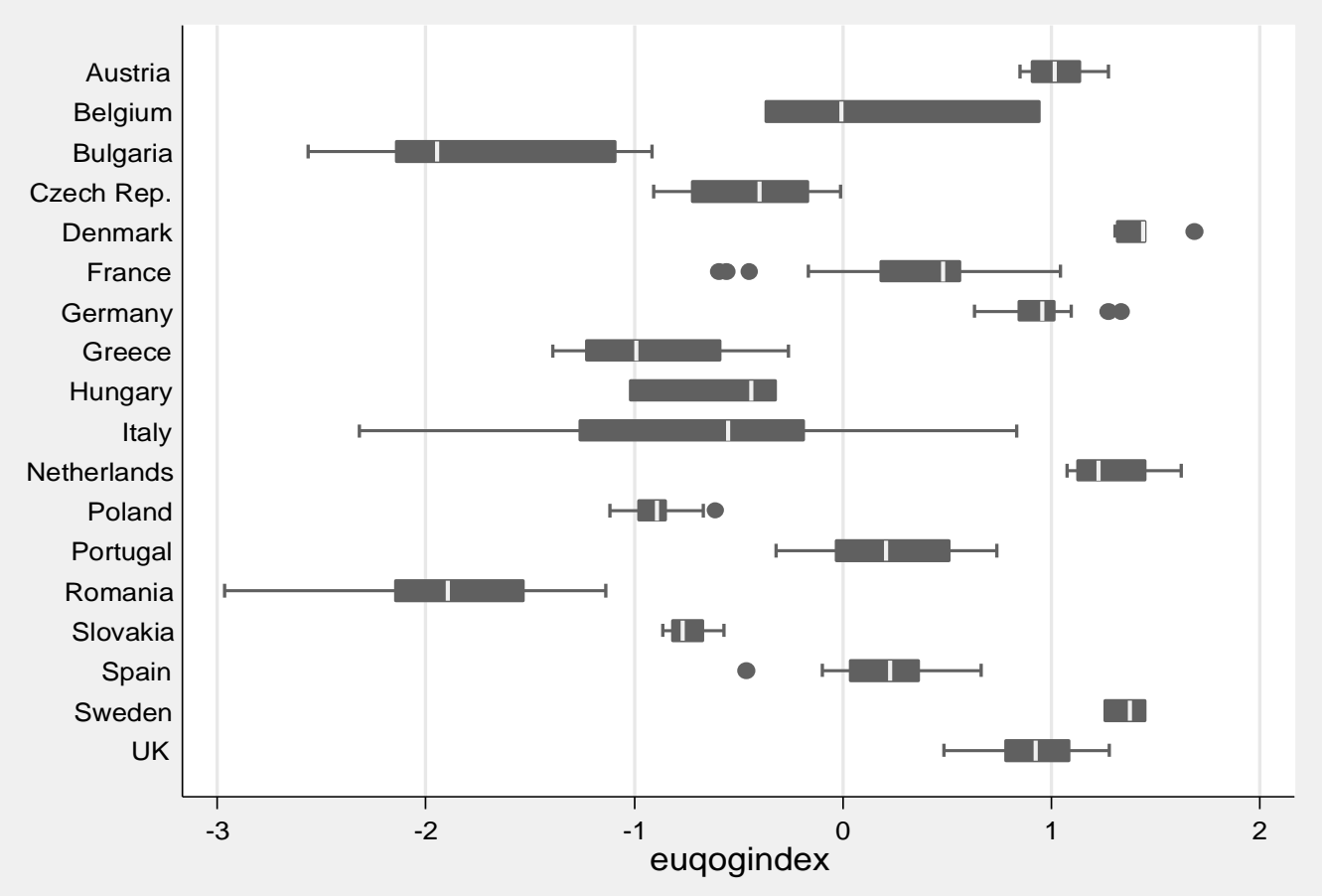

Fig. 1. Regional quality of local public services (reggog) and sub-national variation

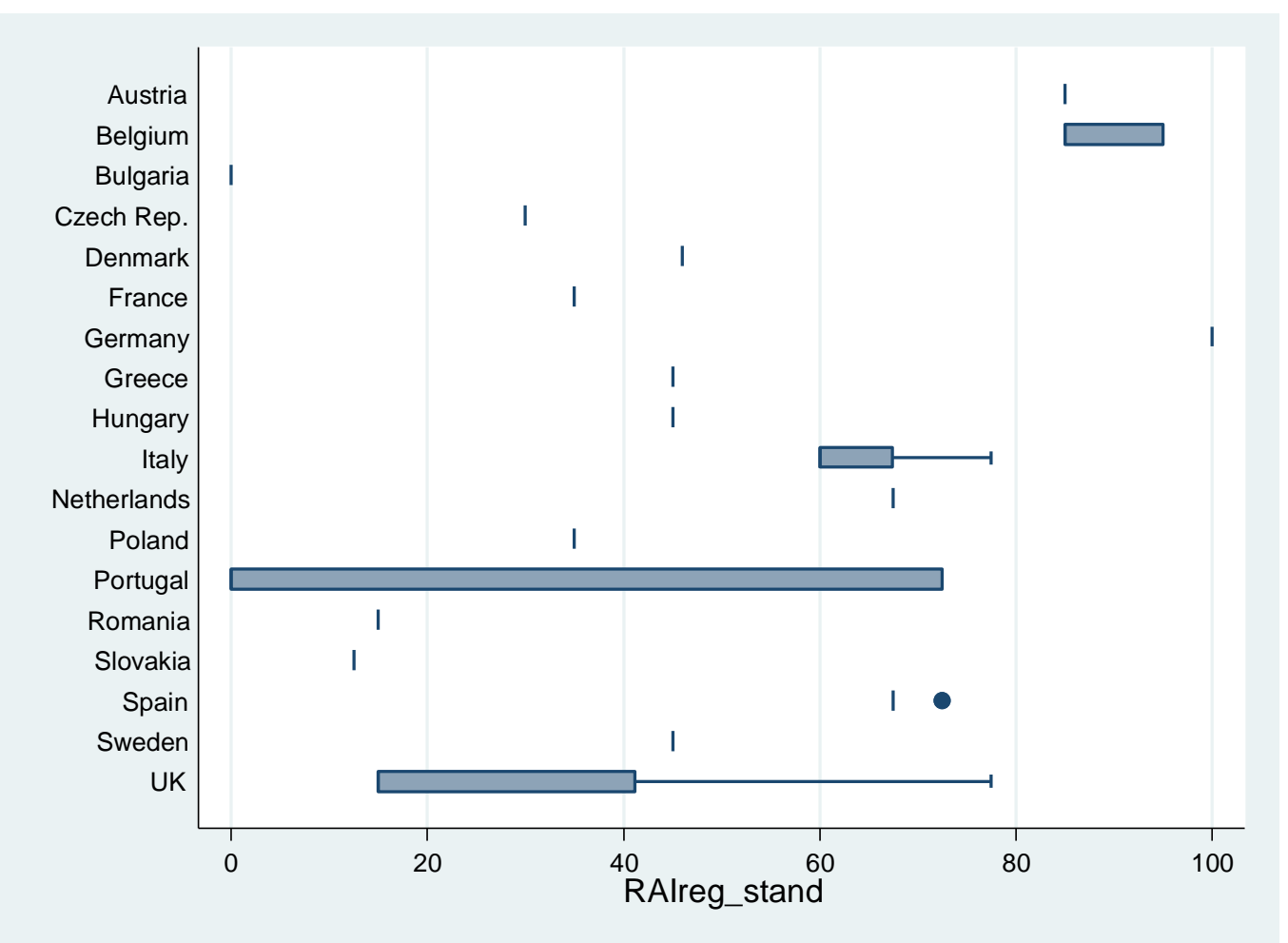

Fig. 2. Degree of regional authority (rai) and sub-national variation 
Table 1. Dose response function of regional autonomy on the performance of local public services and its three pillars- impartiality, lack of corruption, and quality of local services.

\begin{tabular}{|c|c|c|c|c|}
\hline & $\begin{array}{c}(1) \\
\text { Index }\end{array}$ & $\begin{array}{c}\text { (2) } \\
\text { Impartiality }\end{array}$ & $\begin{array}{c}\text { (3) } \\
\text { Lack of corruption }\end{array}$ & $\begin{array}{c}\text { (4) } \\
\text { Quality }\end{array}$ \\
\hline Dichotomy decentralization treatment & $\begin{array}{c}-0.633^{* *} \\
(0.297)\end{array}$ & $\begin{array}{l}0.252 \\
(0.308)\end{array}$ & $\begin{array}{c}-0.756^{* *} \\
(0.314)\end{array}$ & $\begin{array}{c}0.071 \\
(0.301)\end{array}$ \\
\hline Income per capita & $\begin{array}{c}1.591^{* * *} \\
(0.235)\end{array}$ & $\begin{array}{l}0.505^{*} \\
(0.262)\end{array}$ & $\begin{array}{c}1.329 * * * \\
(0.262)\end{array}$ & $\begin{array}{c}1.143^{* * *} \\
(0.226)\end{array}$ \\
\hline Bilingual region & $\begin{array}{c}0.313 \\
(0.202)\end{array}$ & $\begin{array}{c}0.335 \\
(0.282)\end{array}$ & $\begin{array}{l}0.382^{*} \\
(0.207)\end{array}$ & $\begin{array}{c}0.305^{* *} \\
(0.140)\end{array}$ \\
\hline Autonomous region & $\begin{array}{l}0.0996 \\
(0.232)\end{array}$ & $\begin{array}{c}0.224 \\
(0.290)\end{array}$ & $\begin{array}{c}0.298 \\
(0.237)\end{array}$ & $\begin{array}{c}0.002 \\
(0.192)\end{array}$ \\
\hline Capital region & $\begin{array}{l}-0.298 \\
(0.246)\end{array}$ & $\begin{array}{l}-0.274 \\
(0.237)\end{array}$ & $\begin{array}{c}-0.627^{* *} \\
(0.282)\end{array}$ & $\begin{array}{l}-0.274 \\
(0.185)\end{array}$ \\
\hline Population of the region & $\begin{array}{c}-0.434^{* * *} \\
(0.131)\end{array}$ & $\begin{array}{l}-0.028 \\
(0.114)\end{array}$ & $\begin{array}{c}-0.252^{* *} \\
(0.125)\end{array}$ & $\begin{array}{l}-0.162 \\
(0.112)\end{array}$ \\
\hline Size of the region & $\begin{array}{l}0.131^{* *} \\
(0.0635)\end{array}$ & $\begin{array}{c}-0.022 \\
(0.0693)\end{array}$ & $\begin{array}{c}-0.020 \\
(0.0700)\end{array}$ & $\begin{array}{c}0.081 \\
(0.0535)\end{array}$ \\
\hline Eu15 & $\begin{array}{l}-0.0656 \\
(0.293)\end{array}$ & $\begin{array}{l}-0.043 \\
(0.312)\end{array}$ & $\begin{array}{l}-0.313 \\
(0.325)\end{array}$ & $\begin{array}{l}-0.486^{*} \\
(0.262)\end{array}$ \\
\hline Contiguity spillover & $\begin{array}{c}0.012 \\
(0.0200)\end{array}$ & $\begin{array}{c}0.028 \\
(0.0209)\end{array}$ & $\begin{array}{c}0.028 \\
(0.0199)\end{array}$ & $\begin{array}{c}0.025 \\
(0.0159)\end{array}$ \\
\hline Presence of independent media & $\begin{array}{c}-0.057 \\
(0.0625)\end{array}$ & $\begin{array}{c}-0.082 \\
(0.0720)\end{array}$ & $\begin{array}{c}0.088 \\
(0.0649)\end{array}$ & $\begin{array}{c}0.660 * * * \\
(0.0587)\end{array}$ \\
\hline Population with tertiary education & $\begin{array}{c}-0.317^{* *} \\
(0.135)\end{array}$ & $\begin{array}{l}-0.128 \\
(0.130)\end{array}$ & $\begin{array}{c}-0.345^{* *} \\
(0.142)\end{array}$ & $\begin{array}{l}-0.144 \\
(0.134)\end{array}$ \\
\hline Diversity index & $\begin{array}{l}-1.373^{*} \\
(0.809)\end{array}$ & $\begin{array}{l}-0.638 \\
(1.088)\end{array}$ & $\begin{array}{l}-1.300 \\
(0.878)\end{array}$ & $\begin{array}{c}-1.925^{* * *} \\
(0.591)\end{array}$ \\
\hline Country tax decentralization & $\begin{array}{c}0.017^{*} \\
(0.0101)\end{array}$ & $\begin{array}{l}0.076^{* * *} \\
(0.0127)\end{array}$ & $\begin{array}{r}0.045^{* * *} \\
(0.0122)\end{array}$ & $\begin{array}{l}-0.064^{* * *} \\
(0.00929)\end{array}$ \\
\hline Polynomial degree 1 (Tw_1) & $\begin{array}{c}0.0144 \\
(0.0271)\end{array}$ & $\begin{array}{c}-0.187^{* * *} \\
(0.0412)\end{array}$ & $\begin{array}{c}0.0272 \\
(0.0348)\end{array}$ & $\begin{array}{l}-0.0298 \\
(0.0285)\end{array}$ \\
\hline Polynomial degree 2 (Tw_2) & $\begin{array}{l}-0.000812 \\
(0.000547)\end{array}$ & $\begin{array}{c}0.00359 * * * \\
(0.000791)\end{array}$ & $\begin{array}{l}-0.000651 \\
(0.000660)\end{array}$ & $\begin{array}{c}0.000159 \\
(0.000526)\end{array}$ \\
\hline Polynomial degree 3 (Tw_3) & $\begin{array}{c}0.00000664^{* *} \\
(0.00000325)\end{array}$ & $\begin{array}{c}-0.0000206 * * * \\
(0.00000452)\end{array}$ & $\begin{array}{c}0.00000321 \\
(0.00000379)\end{array}$ & $\begin{array}{c}0.00000101 \\
(0.00000292)\end{array}$ \\
\hline test $\_b\left[T w \_1\right]=\_b\left[T w \_2\right]=\_b\left[T w \_3\right]=0$ & $\begin{array}{c}\text { rejected } \\
\text { Prob }>F=0.0048\end{array}$ & $\begin{array}{c}\text { rejected } \\
\text { Prob }>F=0.0001\end{array}$ & $\begin{array}{c}\text { accepted } \\
\text { Prob }>F=0.4937\end{array}$ & $\begin{array}{c}\text { rejected } \\
\text { Prob }>F=0.0006\end{array}$ \\
\hline Observations & 171 & 171 & 171 & 171 \\
\hline R-squared & 0.684 & 0.620 & 0.644 & 0.757 \\
\hline
\end{tabular}

Note: Standard errors in parentheses; ${ }^{*} p<0.10 ;{ }^{* *} p<0.05 ;{ }^{* * *} p<0.01$ 


\section{Dose Response Function}

Outcome variable: euqogindex

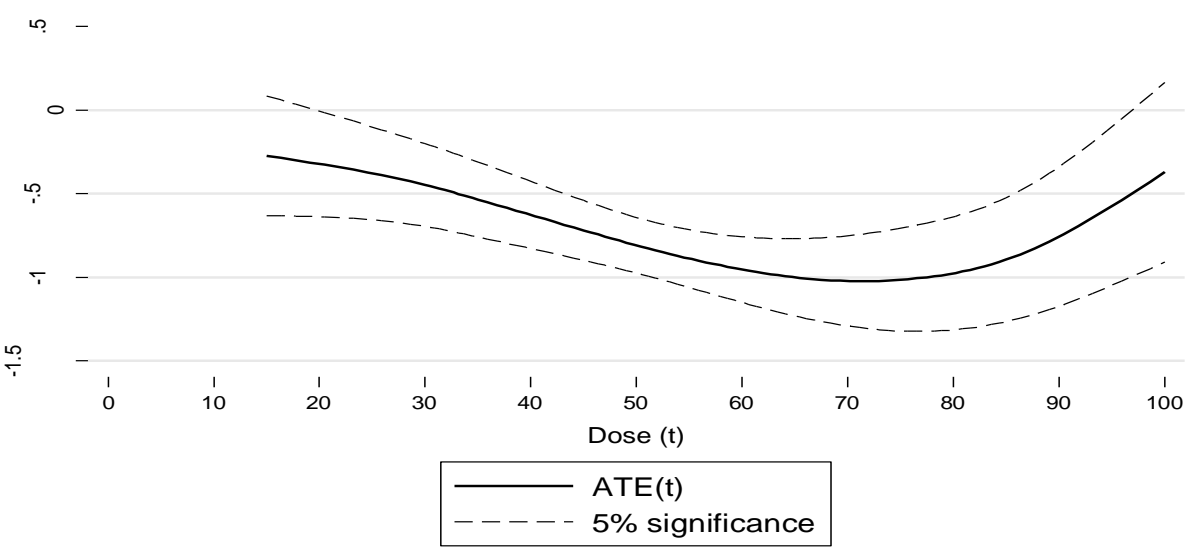

Model: ct-ols

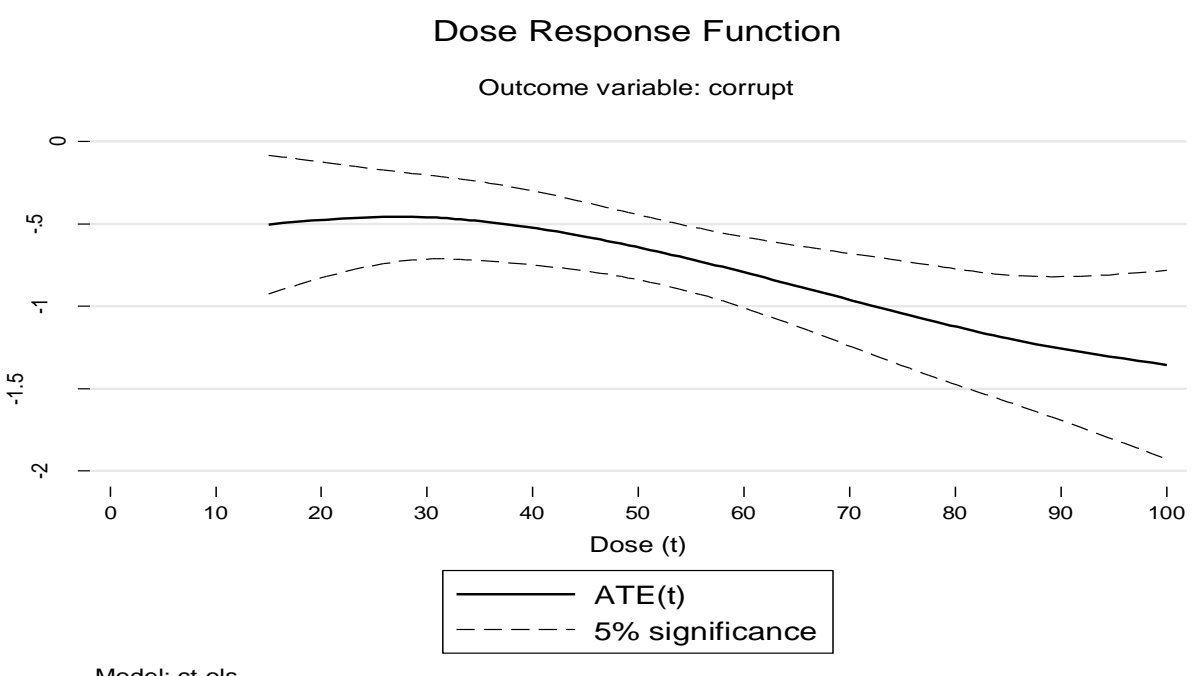

Dose Response Function

Outcome variable: impart

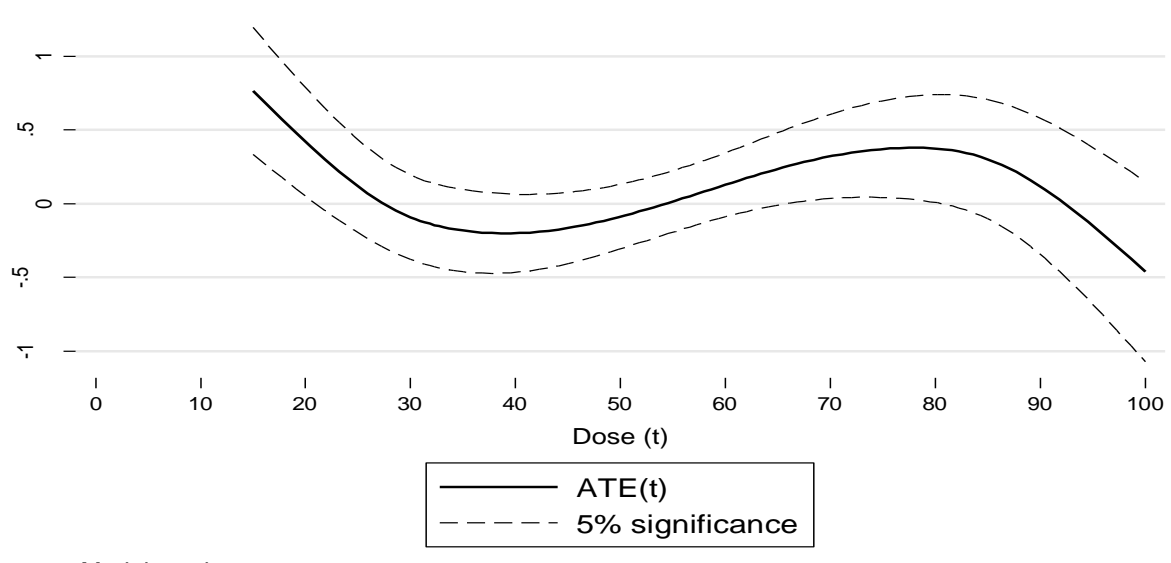

Model: ct-ols

Dose Response Function

Outcome variable: quality

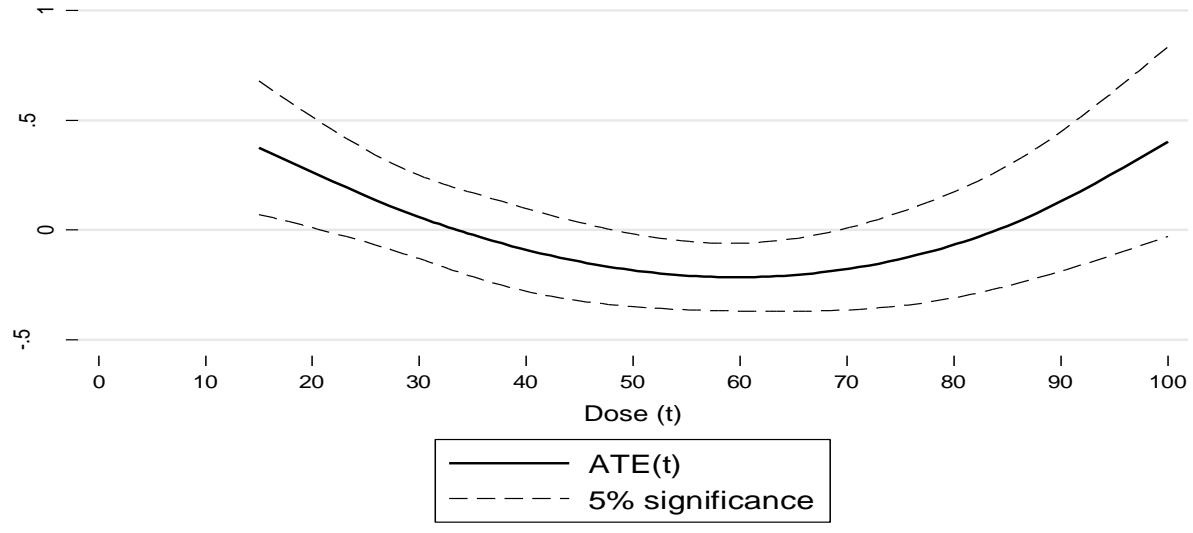

Model: ct-ols

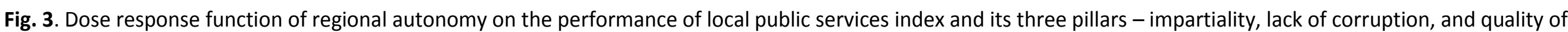
local services. 
Dose Response Function

Outcome variable: euqogindex

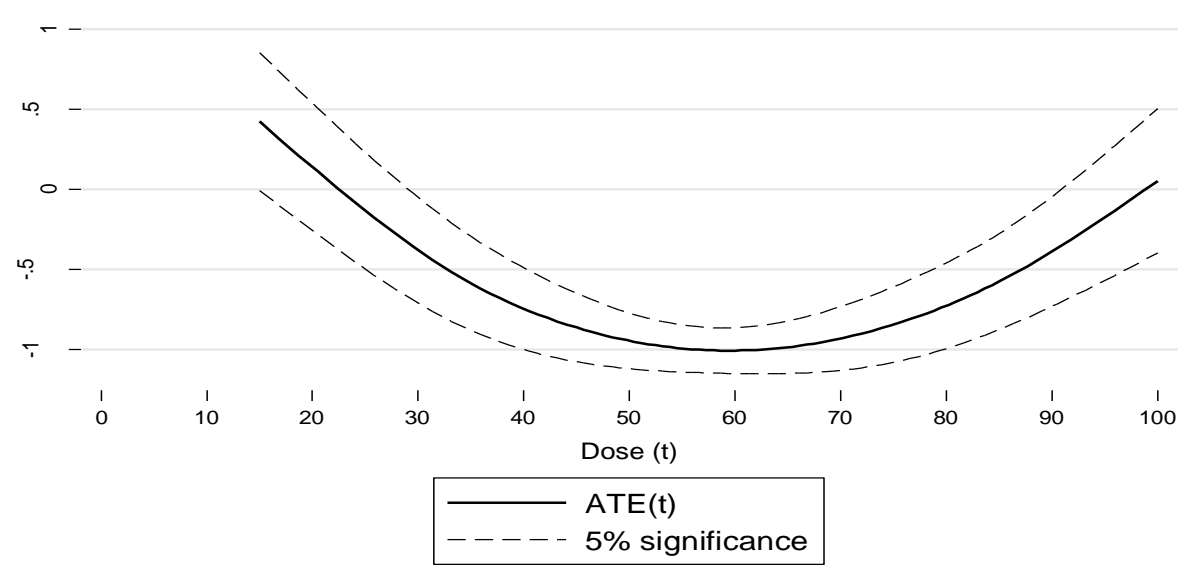

Model: ct-ols

Dose Response Function

Outcome variable: corrupt

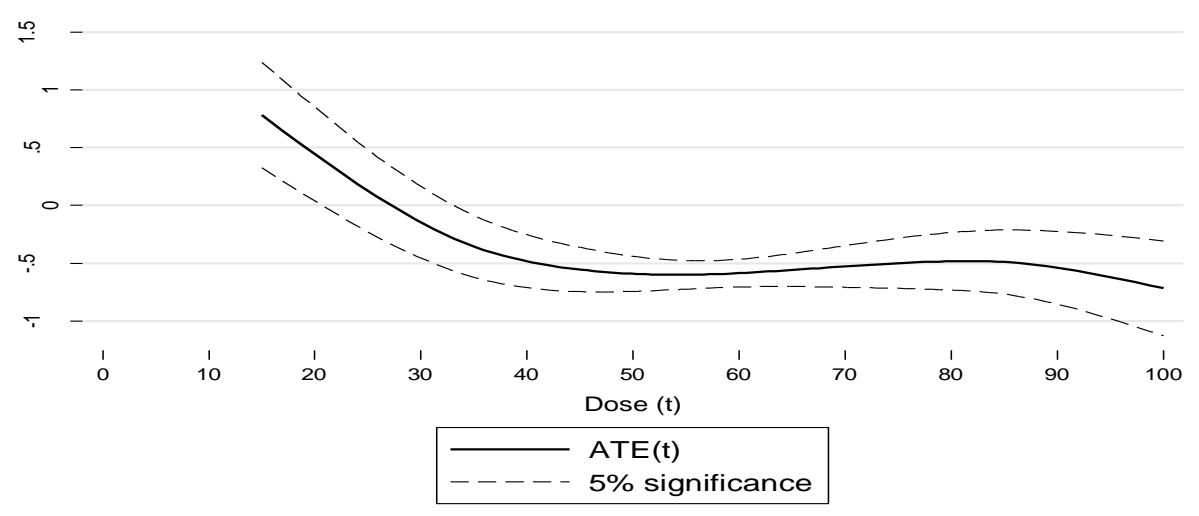

Model: ct-ols

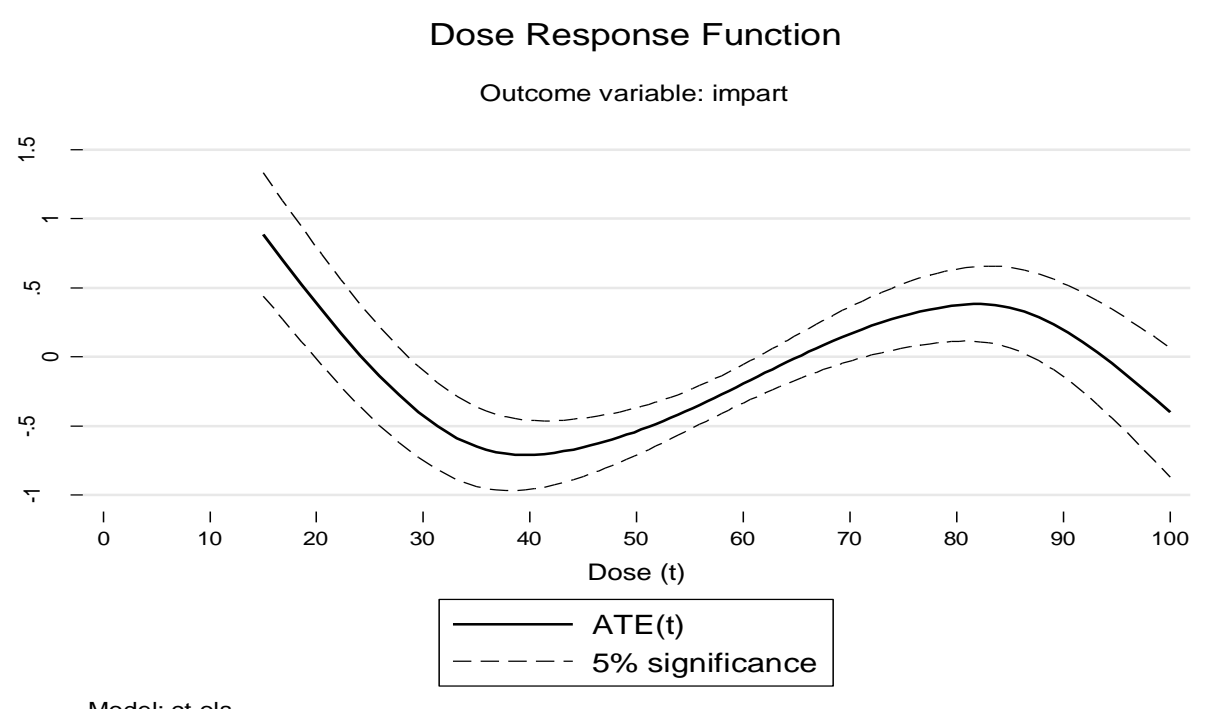

Model: ct-ols

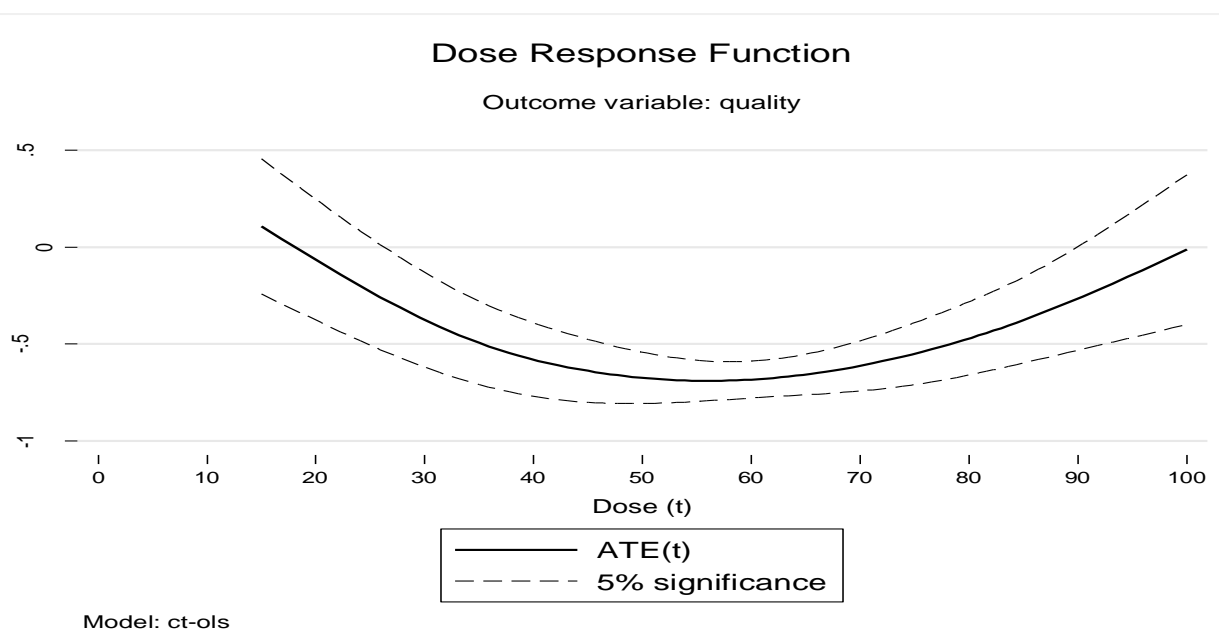

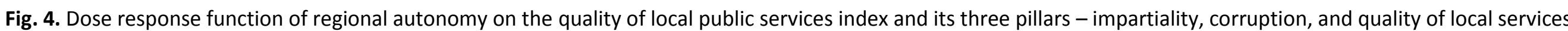
(EU-15 Member countries regions only). 


\section{Dose Response Function}

Outcome variable: euqogindex

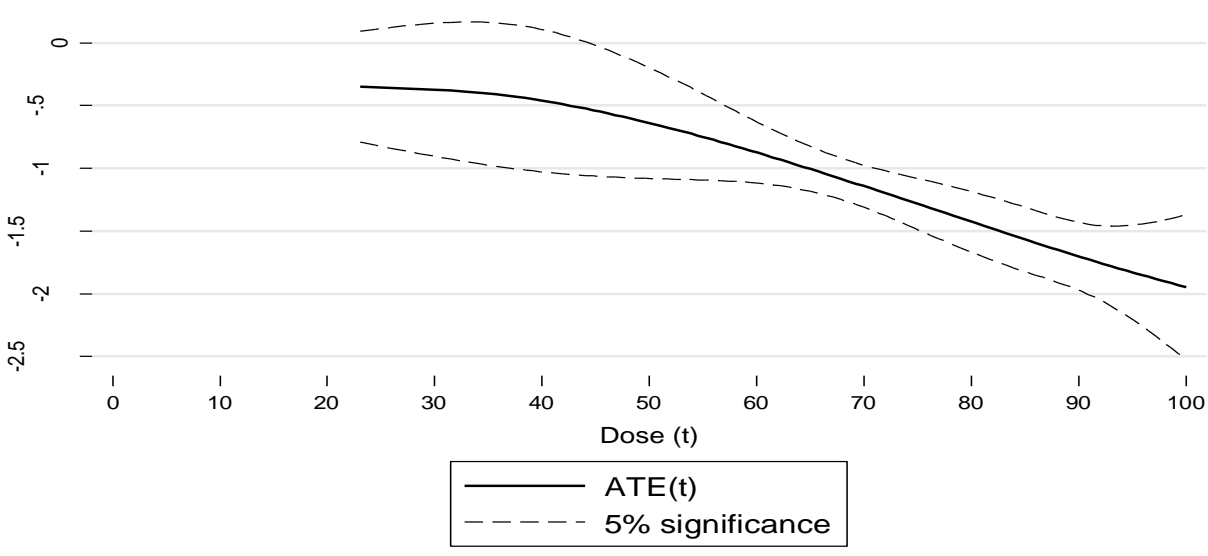

Model: ct-ols

\section{Dose Response Function}

Outcome variable: corrupt

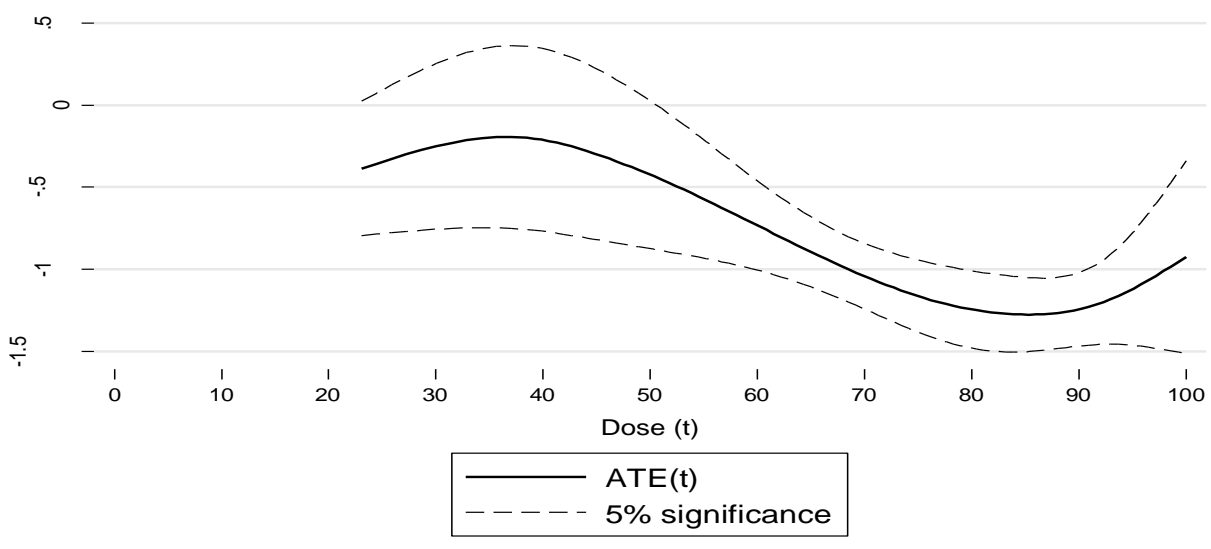

Dose Response Function

Outcome variable: impart

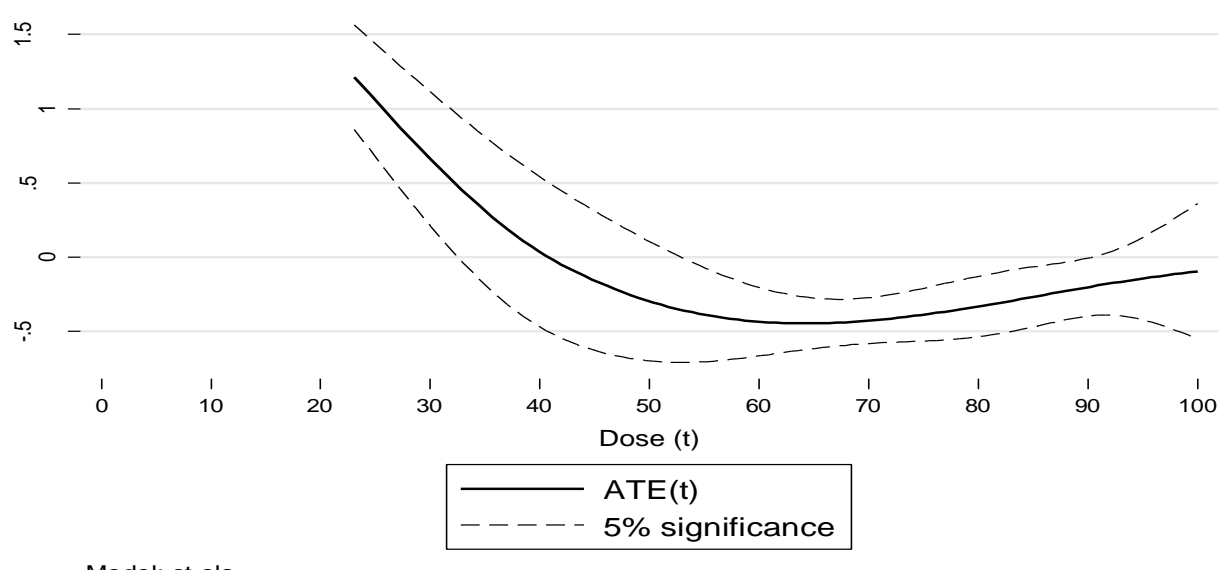

Model: ct-ols

Dose Response Function

Outcome variable: quality

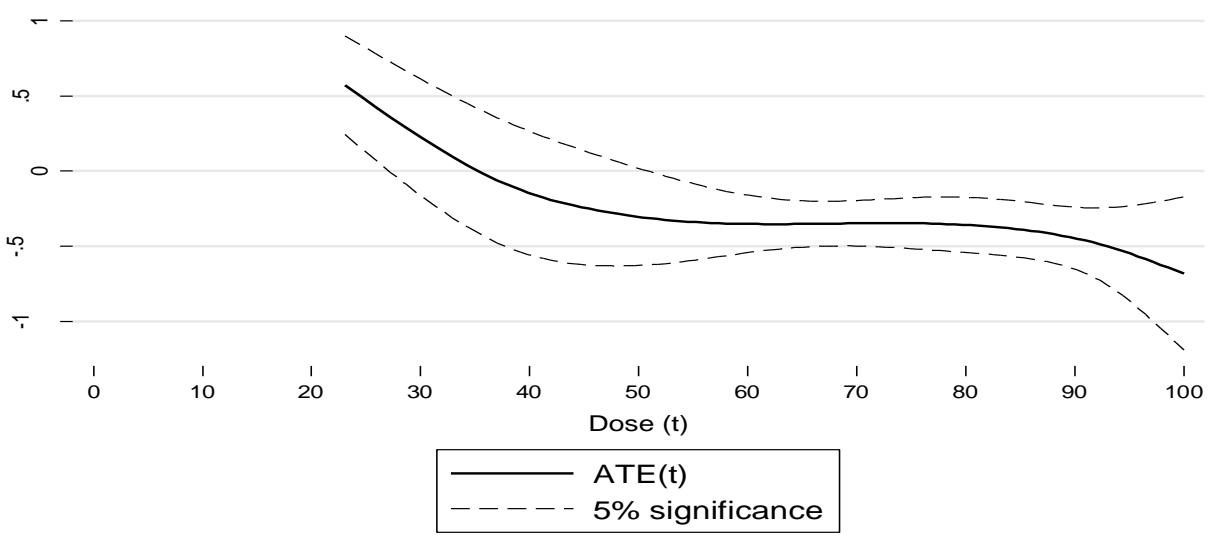

Model: ct-ols

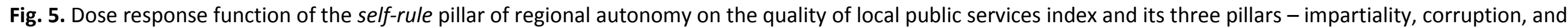
quality of local services. 


\section{APPENDIX}

Table A1. List of variables and descriptive statistics

\begin{tabular}{|c|c|c|c|c|c|}
\hline Variable & Obs. & Mean & Std. Dev. & Min & Max \\
\hline Euqogindex (overall) & 171 & 0.000 & 1.003 & -2.96 & 1.68 \\
\hline Euqogindex (pillar impartiality) & 171 & -0.008 & 0.997 & -2.58 & 2.04 \\
\hline Euqogindex (pillar corruption) & 171 & -0.003 & 1.002 & -3.13 & 2.22 \\
\hline Euqogindex (pillar quality) & 171 & 0.004 & 1.002 & -3.58 & 2.07 \\
\hline Regional authority index (rai) & 171 & 49.020 & 28.189 & 0 & 100 \\
\hline Income per capita (log) & 171 & 9.874 & 0.623 & 8.00 & 11.01 \\
\hline Autonomous region & 171 & 0.088 & 0.284 & 0 & 1 \\
\hline Capital region & 171 & 0.105 & 0.308 & 0 & 1 \\
\hline Population of the region (log) & 171 & 7.557 & 0.890 & 4.79 & 9.80 \\
\hline Size of the region (log) & 171 & 9.526 & 1.112 & 5.08 & 12.65 \\
\hline EU-15 region & 171 & 0.737 & 0.442 & 0 & 1 \\
\hline Contiguity spillover & 171 & 9.824 & 6.173 & 0.00 & 21.00 \\
\hline Share of population with tertiary education (log) & 171 & 3.660 & 0.875 & -5.82 & -1.29 \\
\hline Diversity index & 171 & 0.107 & 0.091 & 0.001 & 0.491 \\
\hline Country tax decentralization & 171 & 12.061 & 7.499 & 0.52 & 26.37 \\
\hline
\end{tabular}


Table A2. Pair-wise correlation among the variables

\begin{tabular}{|c|c|c|c|c|c|c|c|c|c|c|c|c|c|}
\hline & 1 & 2 & 3 & 4 & 5 & 6 & 7 & 8 & 9 & 10 & 11 & 12 & 13 \\
\hline Regional authority index (rai) & 1 & & & & & & & & & & & & \\
\hline Income per capita & 0.560 & 1 & & & & & & & & & & & \\
\hline Bilingual region & 0.222 & 0.187 & 1 & & & & & & & & & & \\
\hline Autonomous region & 0.205 & 0.115 & 0.510 & 1 & & & & & & & & & \\
\hline Capital region & -0.047 & 0.221 & -0.033 & -0.106 & 1 & & & & & & & & \\
\hline Population of the region & 0.017 & 0.068 & -0.063 & -0.195 & 0.166 & 1 & & & & & & & \\
\hline Size of the region & -0.159 & -0.269 & -0.078 & -0.076 & -0.399 & 0.431 & 1 & & & & & & \\
\hline EU-15 region & 0.520 & 0.820 & 0.178 & 0.185 & -0.055 & 0.020 & -0.069 & 1 & & & & & \\
\hline Contiguity spillover & 0.828 & 0.495 & 0.091 & -0.134 & 0.008 & 0.170 & -0.061 & 0.379 & 1 & & & & \\
\hline Presence of independent media & 0.359 & 0.462 & 0.131 & 0.179 & -0.054 & -0.045 & 0.022 & 0.522 & 0.295 & 1 & & & \\
\hline Population with tertiary education & -0.034 & 0.064 & 0.050 & 0.119 & 0.112 & -0.813 & -0.496 & -0.021 & -0.120 & 0.090 & 1 & & \\
\hline Diversity index & 0.399 & 0.583 & 0.299 & 0.058 & 0.269 & -0.080 & -0.303 & 0.483 & 0.301 & 0.215 & 0.132 & 1 & \\
\hline Country tax decentralization & 0.654 & 0.362 & 0.074 & -0.016 & -0.048 & -0.022 & 0.017 & 0.327 & 0.630 & 0.429 & 0.023 & 0.298 & 1 \\
\hline
\end{tabular}


Table A3. Pairwise correlation between the qog index and its three pillars

\begin{tabular}{lcccc}
\hline & Euqogindex & Impartialty & Corruption & Quality \\
\hline \hline Euqogindex & 1 & & & \\
Impartiality & 0.65 & 1 & & \\
Corruption & 0.86 & 0.73 & 1 & \\
Quality & 0.61 & 0.44 & 0.59 & 1 \\
\hline
\end{tabular}

Table A4. Moran autocorrelation test

\begin{tabular}{l|ccccc}
\hline Variables & $\mathrm{I}$ & $\mathrm{E}(\mathrm{I})$ & $\mathrm{sd}(\mathrm{I})$ & $\mathrm{z}$ & $\mathrm{p}$-value \\
\hline Euqogindex & 0.853 & -0.006 & 0.061 & 13.986 & 0.000
\end{tabular}

Note: I=Moran Index; $E(I)=$ expected value of Moran's I under the null hypothesis of no spatial autocorrelation

Table A5. Testing for autocorrelation by using variance inflation factors

\begin{tabular}{lcc}
\hline \multicolumn{1}{c}{ Variable } & VIF & 1/VIF \\
\hline \hline Income per capita & 7.35 & 0.136 \\
EU-15 region & 6.70 & 0.149 \\
Contiguity autonomy & 5.64 & 0.177 \\
Country tax decentralization & 2.59 & 0.386 \\
Size of the region & 2.26 & 0.442 \\
Autonomous region & 2.11 & 0.473 \\
Decentralization (raireg) & 2.10 & 0.476 \\
Capital region & 1.93 & 0.519 \\
Presence of independent media & 1.90 & 0.526 \\
Population of the region & 1.89 & 0.529 \\
Bilingual region & 1.52 & 0.659 \\
Diversity index & 2.52 & 0.485 \\
Share of population with tertiary education & 3.52 & 0.246 \\
\hline
\end{tabular}

Note: we have reported here only the VIF test after the first estimation as for Table 1 (column 1). The VIF test performed for the remaining three models report virtually the same results. 
Table A6. Dose response function of regional autonomy on the performance of local public services and its three pillars for EU 15 regions- impartiality, lack of corruption, and quality of local services.

\begin{tabular}{|c|c|c|c|c|}
\hline & $\begin{array}{c}(1) \\
\text { Index }\end{array}$ & $\begin{array}{c}\text { (2) } \\
\text { Impartiality } \\
\end{array}$ & $\begin{array}{c}\text { (3) } \\
\text { Lack of corruption }\end{array}$ & $\begin{array}{c}\text { (4) } \\
\text { Quality } \\
\end{array}$ \\
\hline \multirow[t]{2}{*}{ Dichotomy decentralization treatment } & $-0.508 *$ & 0.0551 & -0.388 & $-0.397 * *$ \\
\hline & $(0.261)$ & $(0.292)$ & $(0.291)$ & $(0.180)$ \\
\hline \multirow[t]{2}{*}{ Income per capita } & $2.163^{* * *}$ & $0.924^{* * *}$ & $2.107^{* * *}$ & $1.863^{* * *}$ \\
\hline & $(0.299)$ & $(0.322)$ & $(0.291)$ & $(0.232)$ \\
\hline \multirow[t]{2}{*}{ Bilingual region } & 0.344 & 0.290 & 0.345 & 0.232 \\
\hline & $(0.228)$ & $(0.303)$ & $(0.220)$ & $(0.152)$ \\
\hline \multirow[t]{2}{*}{ Autonomous region } & 0.0311 & 0.142 & 0.202 & 0.0145 \\
\hline & $(0.254)$ & $(0.296)$ & $(0.240)$ & (0.199) \\
\hline \multirow[t]{2}{*}{ Capital region } & 0.235 & 0.059 & -0.005 & -0.105 \\
\hline & $(0.281)$ & $(0.283)$ & $(0.276)$ & $(0.178)$ \\
\hline \multirow[t]{2}{*}{ Population of the region } & $-0.566^{* * *}$ & -0.085 & $-0.388 * * *$ & $-0.303^{* * *}$ \\
\hline & $(0.132)$ & $(0.104)$ & $(0.125)$ & $(0.103)$ \\
\hline \multirow[t]{2}{*}{ Size of the region } & $0.213^{* * *}$ & 0.090 & $0.121 *$ & $0.126 * * *$ \\
\hline & $(0.0618)$ & $(0.0667)$ & (0.0638) & $(0.0474)$ \\
\hline \multirow[t]{2}{*}{ Contiguity spillover } & -0.009 & 0.010 & -0.001 & 0.011 \\
\hline & $(0.0206)$ & $(0.0203)$ & $(0.0180)$ & $(0.0141)$ \\
\hline \multirow[t]{2}{*}{ Presence of independent media } & -0.127 & -0.098 & -0.004 & $0.570 * * *$ \\
\hline & $(0.0797)$ & $(0.0835)$ & $(0.0703)$ & $(0.0569)$ \\
\hline \multirow[t]{2}{*}{ Population with tertiary education } & $-0.317 * *$ & -0.050 & $-0.298^{* *}$ & $-0.212^{*}$ \\
\hline & $(0.138)$ & $(0.130)$ & $(0.142)$ & $(0.118)$ \\
\hline \multirow[t]{2}{*}{ Diversity index } & $-2.198 * *$ & -0.616 & $-1.824^{* *}$ & $-2.146 * * *$ \\
\hline & $(0.867)$ & $(1.187)$ & $(0.893)$ & $(0.577)$ \\
\hline \multirow[t]{2}{*}{ Country tax decentralization } & $0.026 * *$ & $0.075^{* * *}$ & $0.052^{* * *}$ & $-0.056^{* * *}$ \\
\hline & $(0.0110)$ & $(0.0142)$ & $(0.0118)$ & $(0.00935)$ \\
\hline \multirow[t]{2}{*}{ Polynomial degree 1 (Tw_1) } & $-0.092 * * *$ & $-0.292 * * *$ & $-0.142 * * *$ & $-0.058^{* *}$ \\
\hline & $(0.0330)$ & $(0.0401)$ & $(0.0317)$ & $(0.0242)$ \\
\hline \multirow[t]{2}{*}{ Polynomial degree 2 (Tw_2) } & 0.000997 & $0.00546 * * *$ & $0.00227 * * *$ & 0.000736 \\
\hline & $(0.000660)$ & $(0.000794)$ & $(0.000638)$ & $(0.000476)$ \\
\hline \multirow[t]{2}{*}{ Polynomial degree $3\left(\mathrm{Tw}_{-} 3\right)$} & -0.00000240 & $-0.0000301 * * *$ & $-0.0000116 * * *$ & -0.00000223 \\
\hline & $(0.00000380)$ & $(0.00000458)$ & $(0.00000374)$ & $(0.00000276)$ \\
\hline \multirow[t]{2}{*}{ test_b[Tw_1] =_b[Tw_2]=_b[Tw_3]=0 } & rejected & rejected & rejected & rejected \\
\hline & Prob $>F=0.00$ & Prob $>F=0.00$ & Prob $>F=0.00$ & Prob $>F=0.01$ \\
\hline Observations & 126 & 126 & 126 & 126 \\
\hline R-squared & 0.599 & 0.653 & 0.644 & 0.778 \\
\hline
\end{tabular}


Table A7. Dose response function of the self-rule component of regional autonomy on the performance of local public services and its three pillars for EU 15 regions-impartiality, lack of corruption, and quality of local services.

\begin{tabular}{|c|c|c|c|c|}
\hline & $\begin{array}{c}1) \\
\text { Index } \\
\end{array}$ & $\begin{array}{c}(2) \\
\text { Impartiality } \\
\end{array}$ & $\begin{array}{c}\text { (3) } \\
\text { Lack of corruption } \\
\end{array}$ & $\begin{array}{c}\text { (4) } \\
\text { Quality } \\
\end{array}$ \\
\hline Dichotomy decentralization treatment & $\begin{array}{c}-1.103^{* * *} \\
(0.316)\end{array}$ & $\begin{array}{c}0.205 \\
(0.310)\end{array}$ & $\begin{array}{c}-0.939 * * * \\
(0.311)\end{array}$ & $\begin{array}{l}-0.0674 \\
(0.279)\end{array}$ \\
\hline Income per capita & $\begin{array}{c}1.477^{* * *} \\
(0.236)\end{array}$ & $\begin{array}{c}0.652^{* * *} \\
(0.241)\end{array}$ & $\begin{array}{c}1.231^{* * *} \\
(0.274)\end{array}$ & $\begin{array}{c}1.300 * * * \\
(0.226)\end{array}$ \\
\hline Bilingual region & $\begin{array}{c}0.184 \\
(0.200)\end{array}$ & $\begin{array}{c}0.405 \\
(0.311)\end{array}$ & $\begin{array}{c}0.284 \\
(0.219)\end{array}$ & $\begin{array}{c}0.221 \\
(0.154)\end{array}$ \\
\hline Autonomous region & $\begin{array}{c}0.260 \\
(0.198)\end{array}$ & $\begin{array}{l}0.496^{*} \\
(0.265)\end{array}$ & $\begin{array}{c}0.313 \\
(0.206)\end{array}$ & $\begin{array}{c}0.102 \\
(0.167)\end{array}$ \\
\hline Capital region & $\begin{array}{c}-0.410^{* *} \\
(0.201)\end{array}$ & $\begin{array}{l}-0.144 \\
(0.262)\end{array}$ & $\begin{array}{c}-0.548^{* *} \\
(0.272)\end{array}$ & $\begin{array}{c}-0.359 * * \\
(0.179)\end{array}$ \\
\hline Population of the region & $\begin{array}{c}-0.381^{* * *} \\
(0.126)\end{array}$ & $\begin{array}{l}-0.156 \\
(0.116)\end{array}$ & $\begin{array}{l}-0.233^{*} \\
(0.119)\end{array}$ & $\begin{array}{l}-0.189^{*} \\
(0.112)\end{array}$ \\
\hline Size of the region & $\begin{array}{c}0.0472 \\
(0.0588)\end{array}$ & $\begin{array}{c}0.0683 \\
(0.0674)\end{array}$ & $\begin{array}{l}0.00276 \\
(0.0663)\end{array}$ & $\begin{array}{c}0.0644 \\
(0.0485)\end{array}$ \\
\hline Eu15 & $\begin{array}{c}0.067 \\
(0.277)\end{array}$ & $\begin{array}{l}-0.131 \\
(0.288)\end{array}$ & $\begin{array}{l}-0.171 \\
(0.337)\end{array}$ & $\begin{array}{c}-0.624^{* *} \\
(0.256)\end{array}$ \\
\hline Contiguity spillover & $\begin{array}{l}0.034^{* *} \\
(0.0163)\end{array}$ & $\begin{array}{l}0.0404^{*} \\
(0.0210)\end{array}$ & $\begin{array}{c}0.0237 \\
(0.0179)\end{array}$ & $\begin{array}{c}0.039 * * * \\
(0.0122)\end{array}$ \\
\hline Presence of independent media & $\begin{array}{c}0.018 \\
(0.0668)\end{array}$ & $\begin{array}{l}-0.148^{* *} \\
(0.0682)\end{array}$ & $\begin{array}{l}0.167 * * \\
(0.0688)\end{array}$ & $\begin{array}{l}0.596 * * * \\
(0.0622)\end{array}$ \\
\hline Population with tertiary education & $\begin{array}{c}-0.313^{* *} \\
(0.137)\end{array}$ & $\begin{array}{r}-0.0738 \\
(0.124)\end{array}$ & $\begin{array}{c}-0.286^{* *} \\
(0.139)\end{array}$ & $\begin{array}{l}-0.155 \\
(0.132)\end{array}$ \\
\hline Diversity index & $\begin{array}{l}-1.197^{*} \\
(0.689)\end{array}$ & $\begin{array}{l}-0.165 \\
(1.033)\end{array}$ & $\begin{array}{l}-1.264 \\
(0.831)\end{array}$ & $\begin{array}{c}-1.979 * * * \\
(0.541)\end{array}$ \\
\hline Country tax decentralization & $\begin{array}{c}0.047^{* * *} \\
(0.0110)\end{array}$ & $\begin{array}{l}0.071^{* * *} \\
(0.0131)\end{array}$ & $\begin{array}{c}0.054^{* * *} \\
(0.0111)\end{array}$ & $\begin{array}{l}-0.048^{* * *} \\
(0.00996)\end{array}$ \\
\hline Polynomial degree 1 (Tw_1) & $\begin{array}{l}0.0342 \\
(0.0865)\end{array}$ & $\begin{array}{l}-0.191^{* *} \\
(0.0776)\end{array}$ & $\begin{array}{c}0.153 \\
(0.0941)\end{array}$ & $\begin{array}{l}-0.148^{* *} \\
(0.0671)\end{array}$ \\
\hline Polynomial degree 2 ( $\left.T w \_2\right)$ & $\begin{array}{r}-0.000820 \\
(0.00164)\end{array}$ & $\begin{array}{c}0.00237 \\
(0.00147)\end{array}$ & $\begin{array}{l}-0.00309 * \\
(0.00176)\end{array}$ & $\begin{array}{l}0.00219^{*} \\
(0.00128)\end{array}$ \\
\hline Polynomial degree 3 (Tw_3) & $\begin{array}{c}0.00000358 \\
(0.00000913)\end{array}$ & $\begin{array}{l}-0.00000917 \\
(0.00000814)\end{array}$ & $\begin{array}{c}0.0000172 * \\
(0.00000980)\end{array}$ & $\begin{array}{c}-0.0000108 \\
(0.00000720)\end{array}$ \\
\hline test $\_b\left[T w \_1\right]=\_b\left[T w \_2\right]=\_b\left[T w \_3\right]=0$ & $\begin{array}{c}\text { accepted } \\
\text { Prob }>F=0.533\end{array}$ & $\begin{array}{c}\text { rejected } \\
\text { Prob }>F=0.00\end{array}$ & $\begin{array}{c}\text { accepted } \\
\text { Prob }>F=0.113\end{array}$ & $\begin{array}{c}\text { rejected } \\
\text { Prob }>F=0.00\end{array}$ \\
\hline $\begin{array}{l}\text { Observations } \\
\text { R-squared }\end{array}$ & $\begin{array}{c}171 \\
0.721\end{array}$ & $\begin{array}{c}171 \\
0.659\end{array}$ & $\begin{array}{c}171 \\
0.655\end{array}$ & $\begin{array}{c}171 \\
0.772\end{array}$ \\
\hline
\end{tabular}

Note: Standard errors in parentheses; ${ }^{*} p<0.10 ;{ }^{* *} p<0.05 ;{ }^{* * *} p<0.01$ 